\title{
Duration of pseudo-stalked barnacles (Xenobalanus globicipi- tis) on a New Zealand Pelagic ecotype orca (Orcinus orca), with comments on cookie cutter shark bite marks (Isistius sp.); can they be used as biological tags?
}

\author{
Ingrid N. Visser ${ }^{1,2^{*}}$,Tracy E. Cooper ${ }^{1,3}$ \& Heiko Grimm ${ }^{1,4}$ \\ ${ }^{1}$ Orca Research Trust, Tutukaka, New Zealand \\ ${ }^{2} \mathrm{https}: / /$ orcid.org/0000-0001-8613-6598 \\ ${ }^{3} \mathrm{https} / / /$ orcid.org/0000-0001-6713-0502 \\ ${ }^{4}$ https://orcid.org/0000-0001-8205-7411 \\ *Corresponding author, e-mail: orca@orca.org
}

\begin{abstract}
This is the first published report of a New Zealand Pelagic ecotype orca (Orcinus orca Linnaeus, 1758, killer whale, Mammalia Cetacea) as a host for the pseudo-stalked barnacle (Xenobalanus globicipitis Steenstrup, 1852, Crustacea Coronulidae). The barnacles were documented on an adult female and she hosted $>79,>3.5$ times higher than any other orca worldwide. They were distributed on her dorsal fin $(n=3)$, pectoral fins $(n=>36)$ and tail flukes $(n=>40)$, with a higher density on her right appendages $(n=>48)$ compared to her left $(n=>28)$. We also document, for the first time, the longevity of $X$. globicipitis hosted on an orca, with a minimum duration of 36 days. We provide a global overview of the distribution of $X$. globicipitis on orca, based on historic and recent publications. In previous reviews (spanning 111 years of records) $X$. globicipitis were documented in ten regions, while we add ten more regions, in just 13 years. This leads us to speculate as to the causes of this rapid increase, which may be linked to observer bias, improved research tools, a change in the distribution of either $O$. orca or X. globicipitis, with distribution of the latter perhaps influenced by oceanic conditions such as marine heatwaves and acidification triggered by climate change. As such, we discuss if either pseudo-stalked barnacles (or bite marks from cookie cutter sharks, Isistius sp., Chondrichthyes Squaliformes) can be used as biological tags or markers for orca ecotypes. We recommend separate management plans for orca ecotypes.
\end{abstract}

KEY WORDS Cookie cutter shark Isistius sp.; killer whale Orcinus orca; pseudo-stalked barnacle; Xenobalanus globicipitis; Pelagic ecotype; spatial and temporal.

Received 06.12.2020; accepted 20.12.2020; published online 30.12.2020

\section{IINTRODUCTION}

Orca (Orcinus orca Linnaeus, 1758, also known as the killer whale, Mammalia Cetacea) are distributed globally, with different ecotypes recognised in many locations, including New Zealand (NZ). For definitions of ecotypes and some examples see Ford et al. (2014) and Riesch (2016). The NZ Pelagic ecotype is recognised by key features such as foraging on marine mammals, pigmentation variations and a high prevalence of cookie cutter shark Isistius sp. bite marks (Visser \& Cooper, 2020a, 2020b). 
The pseudo-stalked barnacle (Xenobalanus globicipitis Steenstrup, 1852, Crustacea Coronulidae), hereafter referred to as Xenobalanus Steenstrup, 1852 has been proposed as a biological tag/marker for cetaceans (Karuppiah et al., 2004; Aznar et al., 2005; Hartny-Mills, 2015; Siciliano et al., 2020), including orca (Whitehead et al., 2014; Matthews et al., 2020). Xenobalanus are filter-feeding cirripedes which are obligate-cetacean epizootics (Fertl $\&$ Newman, 2018) and the barnacle has been documented on at least 34 species of free-ranging and stranded cetaceans (Kane et al., 2008). On orca, they have been documented in a range of geographic locations (Fig. 1). In the following list we use these abbreviations: IS = in situ, where specimens have been documented (e.g., photographed) in the field (on live or stranded hosts) and identification to species level is confirmed or presumed based on external morphological characteristics and attachment to a cetacean host; $\mathrm{ES}=$ ex situ, where specimens have been collected from a cetacean host and identification to species level is confirmed from morphological external/internal characteristics and/ or dissection and/or DNA:

Australia (Donnelly et al., 2018, IS), Brazil (Siciliano et al., 2020, IS), California (Samaras, 1989,
ES; Black et al., 1997, IS), Canadian Arctic (Matthews et al., 2020, IS), Canary Islands (Foote et al., 2011, IS), Chile (Cortés Peña, 2019, IS), Costa Rica (Fertl et al., 1996, IS), Eastern Tropical Pacific (Pitman et al., 2007, IS; Kane et al., 2008, IS; Olson \& Gerrodette, 2008, IS), Galápagos Islands (Denkinger \& Alarcon, 2017, IS), Gibraltar (CIRCE, 2020, IS) we note that an earlier record attributed to Gibraltar should be listed as Spanish, see S-1 for details, Guatemala Basin (Olson \& Gerrodette, 2008, IS), Japan (Sakai Y. et al., 2009, ES) [we note that Sakai Y. et al. (2009) at page 82, erroneously claim that their record from an orca captured off Kii Peninsula, Japan in "winter, 1988", "appears [to be] the first record of X. globicipitis from killer whale"; however, the Japan specimen was preceded by the Monaco specimen (Richard \& Neuville, 1897) and the Spanish specimen (Gruvel, 1920) (see S-1 for details) and by the California specimen (Samaras, 1989)], Monaco (Richard \& Neuville, 1897, ES; Gruvel, 1920, ES; Richard, 1936, ES; Richard \& Neuville, 1936, ES); Mexico (Black et al., 1997, IS; Guerrero-Ruiz \& Urbán, 2000, IS; Olson \& Gerrodette, 2008, IS; VargasBravo et al., 2020, IS), Peru (Olson \& Gerrodette, 2008, IS; Pacheco et al., 2019, IS), South Africa

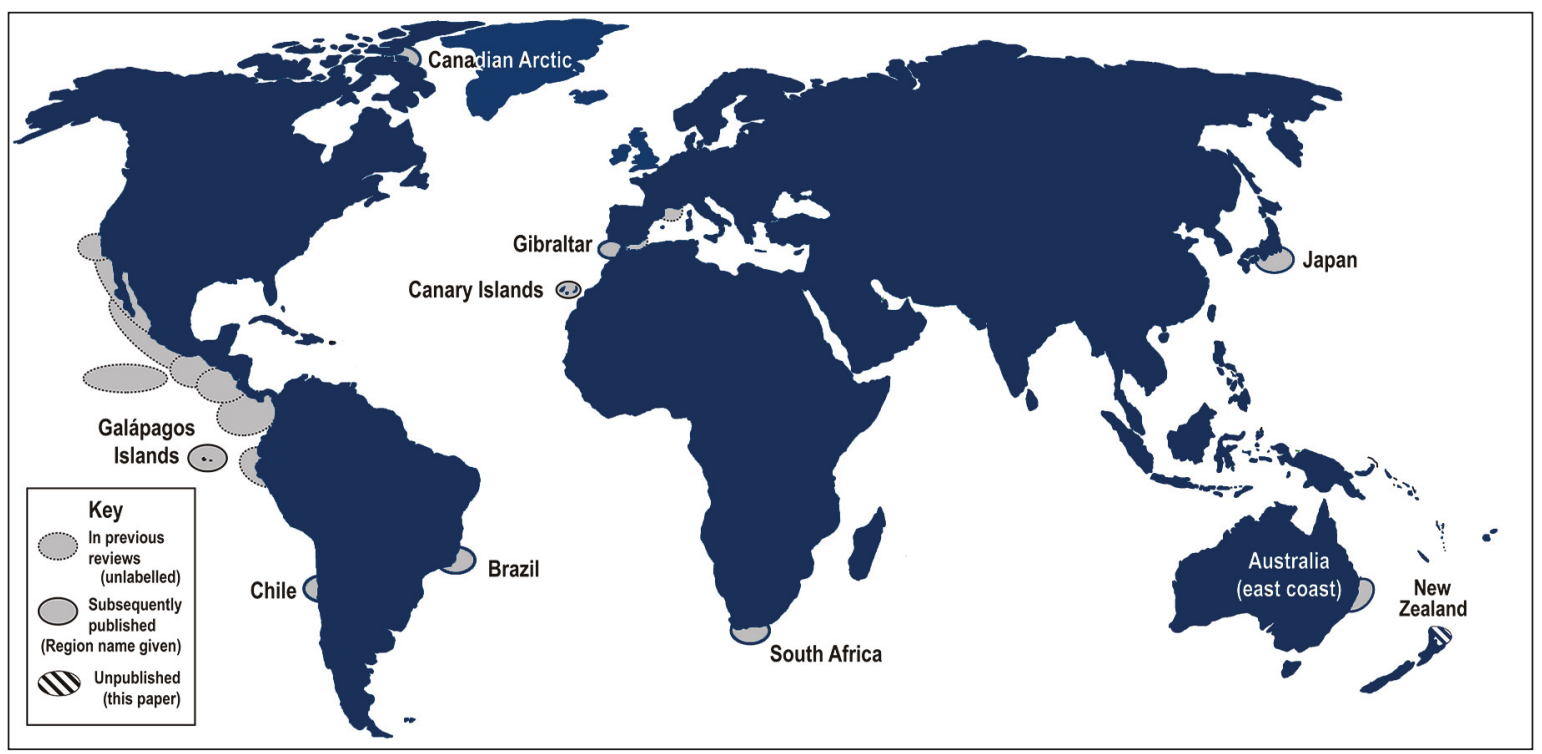

Figure 1. Regions where Xenobalanus globicipitis have been documented on orca (1896-2020, see text for details). The 10 regions identified in Rajaguru \& Shantha (1992) and Kane et al. (2008) during a 111-year period are indicated by unlabelled grey areas with a dotted border. Since Kane et al. (2008), 10 additional regions (labelled with region name, indicated by grey and striped areas) have been added in just 13 years. The size of the areas approximates the general region only (e.g., the Monaco area is for one record, yet extends outwards). 
(Best, 2007, ES; Whitehead et al., 2014, IS) and Spain (Gruvel, 1920, ES; Richard, 1936, ES).

One of the earliest records of Xenobalanus on orca is from 27 May 1896, off Monaco in the Mediterranean Sea, when two female orca $(5.90 \mathrm{~m}$ and $4.10 \mathrm{~m}$ in length) from a group of three individuals, were harpooned and killed (Richard \& Neuville, 1897). See S-1 for details of this record as Richard (1936) is often erroneously cited as the author.

The authors reported that 'several Xenobalanus were attached to the tail and pectoral of the large Orca' [translated]. That orca also had large pieces of cetacean(s), including fragments of flesh still covered with skin as well as large pieces of skin, some nearly a metre in length, inside the stomach.

Six years later, on 22 July 1902 off La Chullera, Spain, another female orca (4.70 m long) was harpooned and killed (Gruvel, 1920; Richard \& Neuville, 1936) (see S-1 for details of this record as Richard (1936) is often erroneously cited as the author, however both Gruvel (1920) and Richard \& Neuville (1936) have details of this capture) and she had an unspecified number of Xenobalanus on both pectoral fins as well as on her tail flukes. Inside her stomach were large $(1-2 \mathrm{~kg})$ pieces of fish and bones that were speculated to be from tuna or swordfish.

The different food types found in the stomach of these two individuals is indicative of different orca ecotypes (i.e., mammal- and fish-eating populations). As another distinguishing feature, the presence of Xenobalanus on orca may be markers for the distribution of and/or different ecotypes (Whitehead et al., 2014; Matthews et al., 2020).

\section{METHODS}

\section{Study methods}

As part of the long-term (nearly three decades) study of NZ orca, carried out by the Orca Research Trust (www.orcaresearch.org), opportunistic sightings of orca are attended. The date (in yyyymmdd format), location of the encounter, water temperature and environmental conditions are documented, the animals are photographed and/or videoed and behavioural observations collected. Video is typically collected using a HD GoPro Hero ${ }^{\circledR}$ camera on a pole, which can be placed underwater. Subsequently, frames from the video can be extracted for analysis. In addition to these dedicated research encounters, sighting records (including photographs/videos) are collected on an ad hoc basis from citizen scientists and marine mammal tour operators (see Visser, 2000 for details).

Individual orca are identified using congenital and acquired marks/pigmentation and are then assigned catalogue numbers (see Visser, 2000 for details). They are also classified into one of the orca populations documented in NZ waters, based on a range of features such as pigment variations and a prevalence of cookie cutter shark (Isistius sp.) bite marks (Dwyer \& Visser, 2011; Visser \& Cooper, 2020a, 2020b).

\section{Identification of the orca NZOP-005}

The subject of this publication is an adult female Pelagic ecotype (catalogue identification number NZOP-005, also known as "Māia", a Māori name meaning "brave", "bold", "capable" and "confident"). She was identified using inter alia; (i) asymmetrical saddle patches (Figs. 2, 3) similar to some of the orca described in Mäkeläinen et al. (2013). On the left side she had what is classified as a "smooth" saddle patch (Fig. 2) and on her right side an "open" saddle patch with a "vertical notch" (Fig. 3) as described in Sugarman (1984) and Baird \& Stacey (1988). She also had a band of four parallel marks (Figs. 4-6) which, based on their spacing, most likely were a result of "rake marks" from conspecifics teeth; see Scheffer (1969) and Visser (1998) for examples.

Additionally, NZOP-005 had cookie cutter shark bite marks, one of which resulted in an indent which spanned across her spinal ridge, resulting in the scar being visible on both sides of the animal (Figs. 2-6). The bite mark would be classified by Dwyer \& Visser (2011) as "SCAR: completely healed wound, typically with change in original skin pigmentation colour". See Dwyer \& Visser (2011) for details regarding identification of scars and wounds from these sharks. The indent was $\sim 7 \mathrm{~cm}$ long (based on measurements of similar cookie cutter shark bite marks on necropsied orca, Visser \& Orca Research Trust, unpublished data).

\section{Xenobalanus globicipitis}

We identified Xenobalanus from the morpho- 


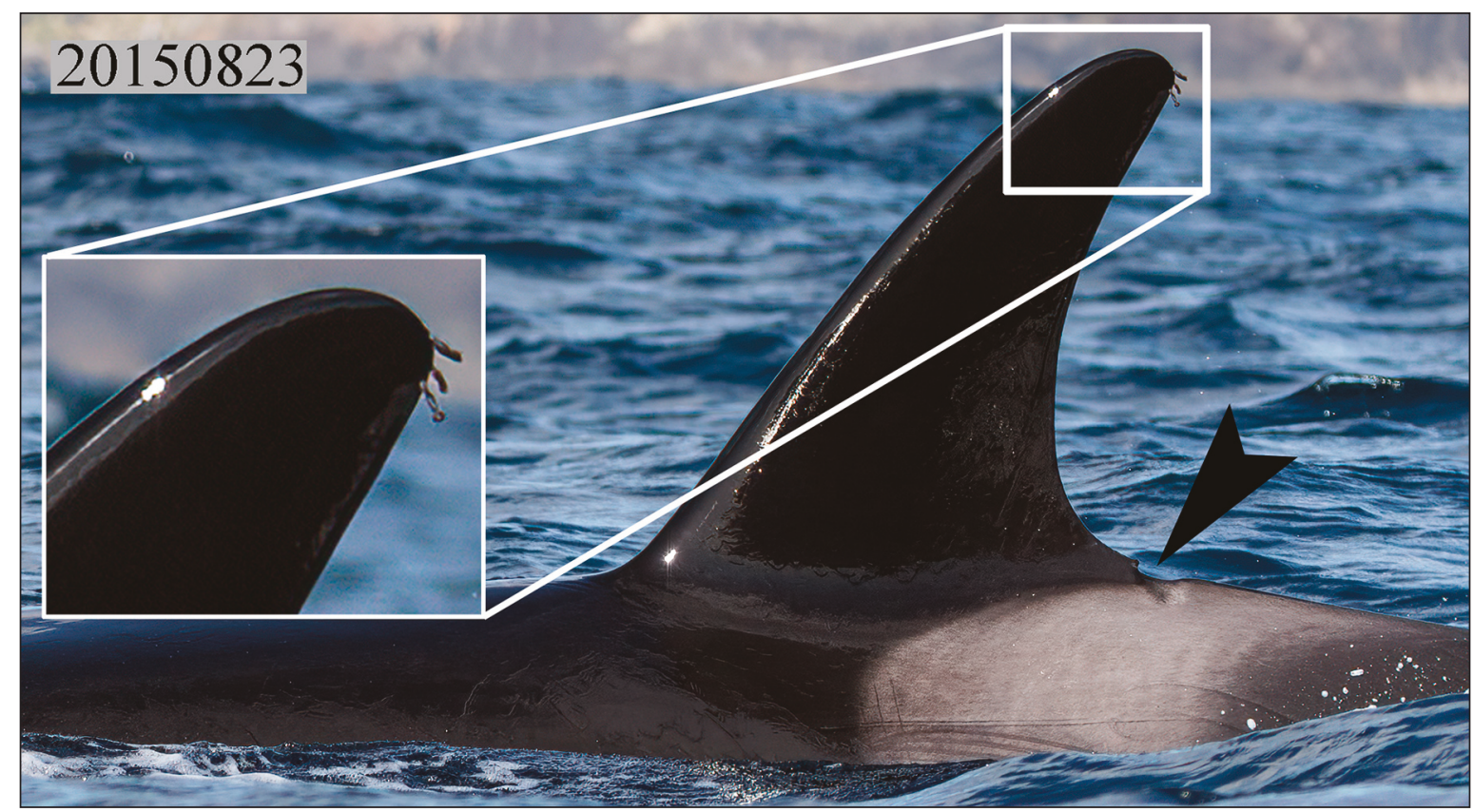

Figure 2. NZOP-005 on 20150823, photographed off Cape Brett, Bay of Islands, east coast Northland. She was host to three Xenobalanus globicipitis barnacles on the trailing edge of her dorsal fin, near the tip (see insert for details of dark pigmentation of the barnacle, one of the distinguishing features of this species). Note the indent in the spinal ridge near the base of the fin which extends into the saddle patch (black arrow). This was from a cookie cutter shark (Isistius sp.) bite mark and used to cross match this orca between years and confirm matches from left and right sides. Photo by HG.

logical features visible in photographs and compared those to published images, anatomical drawings and descriptions in published literature (e.g., Steenstrup, 1852; Darwin, 1854; Bane \& Zullo, 1980; Rajaguru \& Shantha, 1992; Pugliese et al., 2012; Fertl \& Newman, 2018; Dreyer et al., 2020). For example, Darwin (1854: 440), states "The whole surface is smooth, and is formed by rather thin membrane, of an orange colour; but from the colour of the underlying corium, the whole appears of a dark chocolate red, the reflexed hood being rather lighter coloured". Bane \& Zullo (1980) describe the colour as "uniform reddish purple color, except for the cream-to-buff-colored basal attachment disk". Pugliese et al. (2012) focused on describing the attachment plates and mentioned "calcified attachment plates" which display "foliate projections". Darwin's (1854, fig. $4 a)$ is remarkable in its detail and an accurate depiction of what is seen in the dissecting microscope photographs in Pugliese et al. (2012, their Fig. 1), however they describe the shape as "Each footplate radiates out from the central pedicle and together leading to the formation of what resem- bles a flower-shaped rather than star-shaped (Rajaguru and Shanta, 1992) attachment organ". Carrillo et al. (2015) provide a close-up photograph of at least eight attachment shells from the flukes of a dead striped dolphin (Stenella coeruleoalba, Meyen, 1833) which show star-shaped attachment shells with rounded lobes, similar to a flower shape. Siciliano et al. (2020) also used photographs to identify Xenobalanus on cetaceans in situ, including orca, and noted "The genus Xenobalanus is monotypic, and the most similar barnacle genus is Conchoderma von Olfers, 1814, with four recognized species, of which two, C. auritum (Linnaeus, 1767) and C. virgatum Spengler, 1789, were registered on cetaceans, settling in hard substrata such as teeth and sessile barnacles. Thus, X. globicipitis was identified by its narrower peduncle and darker colouration and its settlement in soft substrate" [citations excluded].

Therefore, the features we used to assess the specimens in situ were inter alia; location on the cetacean host (i.e., typically on (or very near to) the trailing edges of orca appendages); smooth skin; cylindrical shaped and flexible body ('stalk'); a red- 

(Orcinus orca), with comments on cookie cutter shark bite marks (lsistius sp.); can they be used as biological tags?

brown-purple colouring of the body; a paler coloured 'hood'; cirri; the shell or basal attachment plates being small, radiating out laterally from the base of the body and exhibiting a star/flower-shaped structure with irregular and/or rounded lobes; shell, whitish-cream in colour.

We note that although copepods of the genus Pennella may superficially resemble Xenobalanus, we believe that the specimens recorded on the orca were Xenobalanus based on comparative features (e.g., Fraija-Fernández et al., 2018).

We counted the number of Xenobalanus on each appendage by using photographs which were postprocessed using machine-learning TopazLabs (https://topazlabs.com/) AI software for sharpening, stabilizing and upsizing. Each image was run through multiple iterations using various combina- tions to produce an image in which the bases/heads of the Xenobalanus were most visible. The Supplemental Material S-2 gives more details and examples. We then compared right to left sides of NZOP-005 to assess asymmetry in the distribution of the barnacles.

\section{RESULTS}

\section{Pigmentation, rake marks \& cookie cutter shark bite marks}

NZOP-005 was photographed on six occasions between 2008 and 2019 (i.e., 4,090 days (or 11 years, 2 months, 12 days) apart; Table 1, Figs. 215 , and see "Identification of the orca NZOP-005"

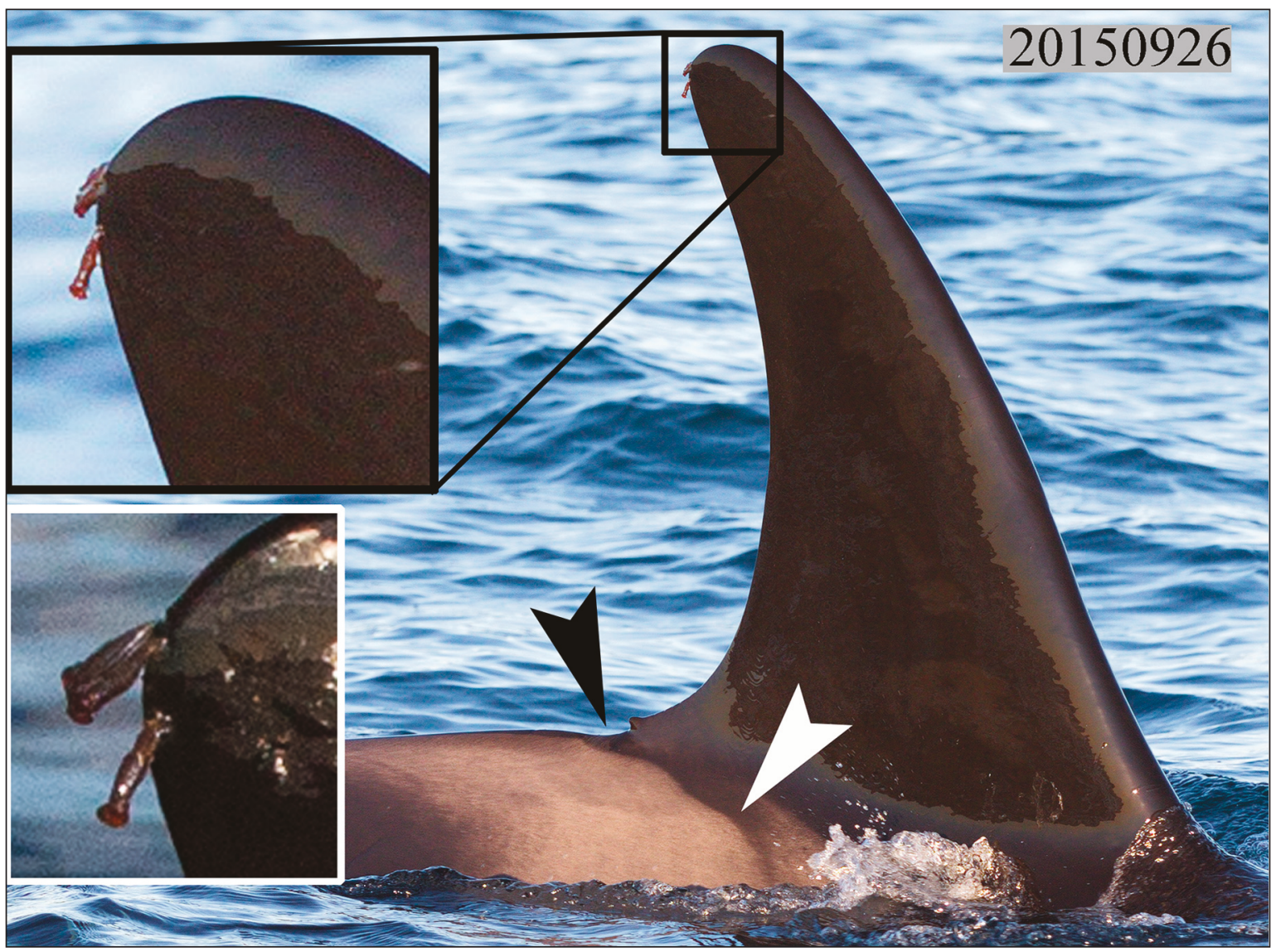

Figure 3. NZOP-005 photographed on 20150926, in the Hauraki Gulf, 165 km to the south of her previous sighting. Three Xenobalanus globicipitis barnacles are on her dorsal fin (the third is partially obscured, top insert). The lower insert is from the same day, but a different photograph. The indent on her spinal ridge is visible (black arrow). The duration between the sighting in figure 2 and this sighting is 35 days. Also note the 'open' saddle patch (white arrow, see text for details). Photographs by INV. 
for details. In the higher-resolution images of 2015 and 2019 (Figs. 5, 6) the band of four parallel rake marks were visible for at least 1,529 days (or 4 years, 2 months, 7 days) (Figs. 5, 6, white arrows). In the lower resolution image from 2008 (Fig. 4), the rake marks are possibly present (white arrow), but they cannot be confirmed, therefore that date was not included in the calculation.

The cookie cutter shark bite mark remained a consistent identifying feature across the years (Figs. 4-6, black arrows). An additional cookie cutter shark bite mark, lower down on her left saddle patch was visible for the same period of time (Figs. 4-6, circled). When NZOP-005 was photographed on 20191029, a third cookie cutter bite mark was visible on her left saddle patch (Fig. 6, insert). Both marks would also be classified as "SCAR", with the latter having a dark pigmented 'ring' around it (Fig. 6 , insert).

\section{Xenobalanus globicipitis}

Although NZOP-005 was photo-identified for the first time in August 2008 in the Bay of Islands,
Northland (record \#1, Table 1, Fig. 7), the images from that encounter were of insufficient resolution to determine if Xenobalanus were present (Fig. 4). She was resighted just over one year and seven months later (in March 2010, record \#2, Table 1, and see Visser et al. (2010)), within only a few kilometres of the first sighting and no Xenobalanus were photographed or noted. Next, NZOP-005 was photographed five and half years later (in August 2015, record \#3, Table 1, Fig. 7), and at that point she was photographed with three Xenobalanus on her dorsal fin (Figs. 2, 5). This sighting was only $\sim 17 \mathrm{~km}$ from the two previous sightings in the Bay of Islands). Subsequently, 35 days later (in September 2015, record \#4, Table 1, Fig. 7) she was photographed to the south in the Hauraki Gulf, $\sim 165$ $\mathrm{km}$ from the Bay of Islands. On that day her tail flukes were first photographed and a small rounded notch was observed on her right fluke (Figs. 8, 9, blue arrows) along with a shallow section missing from the trailing edge (Figs. 8, 9, green arrows). At least 40 barnacles were visible along the trailing edge ( $>26$ on the right and $>14$ on the left fluke, Fig. 8, Table 1 and see Supplemental Material S-2).

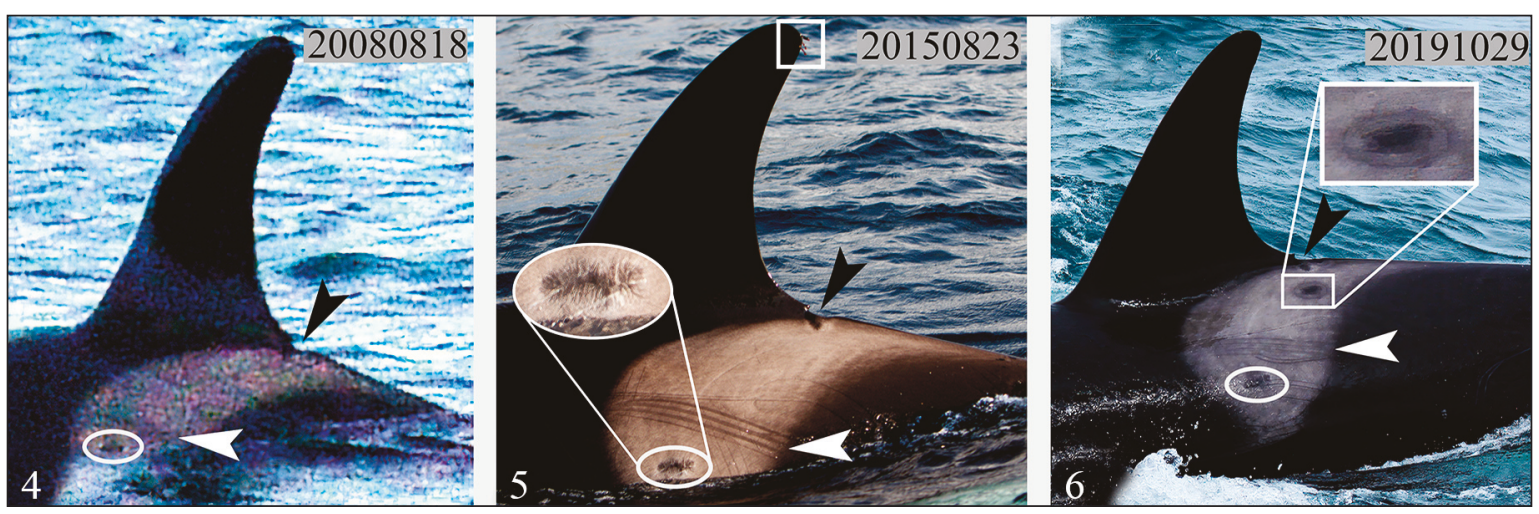

Figures 4-6. When NZOP-005 was first photographed on 20080818 (Fig. 4, left), although the resolution of the image was very low, when compared to subsequent Figs. 5, 6 it is possible to locate two cookie cutter shark bite marks (CCSBM); one on her spinal ridge (black arrow) and one low on her left saddle patch (circled). In figure 4 there is possibly a dark band of rake marks from conspecifics teeth (white arrow and see Figs. 5, 6, for placement). When next photographed on 20150823 (Fig. 5), the higher resolution image shows three Xenobalanus globicipitis on the tip of her dorsal fin (square, see also Fig. 2). The two CCSBM are still visible, with the typical 'puckering' of one these scars now visible (insert). The rake marks are clearly visible as four parallel darker pigmentation lines (white arrow). Four years, two months and seven days later, she was photographed on 20191029 (Fig. 6), and she had no barnacles on her dorsal fin. The two CCSBM remained visible (black arrow and circle, with the latter obscured slightly by the light reflection). She had acquired a new CCSBM on her left saddle patch with a dark ring of pigmentation surrounding it (insert). The original four rake marks had faded somewhat and she had acquired new rake marks below them (white arrow). The total duration that the spinal ridge and left saddle CCSBM (and potentially the rake marks), were documented was 4,090 days (i.e., 11 years, 2 months, 12 days), which exceeds the previous published record of 1,158 days (Dwyer \& Visser, 2011). Photographs by Jochen Zaeschmar (left) HG (middle) and Auckland Whale and Dolphin Safari, Andy Light (right). 
They were spread along nearly the entire span of both flukes, but in some places clustered tightly together along the trailing margin (Figs. 8-10). Due to that clustering, the number of barnacles estimated was conservative because tightly clustered individuals obscured conspecifics (see Supplemental Material S-2 for examples).

The following day (i.e., 20150927, record \#5, Table 1, Fig. 7), she was resighted $\sim 4.5 \mathrm{~km}$ to the east and underwater video was obtained using a HD pole-cam. As NZOP-005 made a number of passes close by the boat, both sides of her body as well as her tail flukes were documented. Again, numerous Xenobalanus were documented on the trailing edge of her tail flukes (Fig. 11) while on the distal edge of her right pectoral fin there were $>22$ (Fig. 12) and on the left $>14$ (Fig. 13).

We could see no barnacles on any other part of her body. Of note is that many of the Xenobalanus in the underwater images appear to have pale body colouring, however a comparison between the topside photographs showing the red-brown colouring of the body of the barnacles and the subsequent underwater video frames (with the paler colour), illustrate this is an artifact of colour absorption by the water. This is due to the light absorption and scattering properties of water whereby red light, which is a long-wavelength light and is the most affected, is reduced to $\sim 1 / 3$ of its intensity after just a metre's distance (Xinwei et al., 2015).

There was a noticeable difference in the number of Xenobalanus on her right and left sides (Table 1, Table 2, Figs. 8, 9, 11-13 and see Supplemental Material S-2). We could find only limited records in the literature where the numbers of Xenobalanus on both right and left were documented for individual cetaceans, of any species (Table 2).

The duration of attachment of Xenobalanus, as well as the potential settlement and/or rapid growth is suggested by records $\# 3$, \#4 and \#5, as although NZOP-005 was documented with three Xenobalanus on her dorsal fin during all three encounters, there were some discrepancies. In figure 14 the bases of the three barnacles are approximately equidistant from each other. However, although barnacles ' $\mathrm{A}$ ' and ' $\mathrm{B}$ ' may have remained attached between all three sightings, it is apparent that at least one barnacle (labelled as barnacle ' $\mathrm{C}$ ' in figure 14), although present in August is no longer present in September, and instead, a scar remains (Fig. 15).

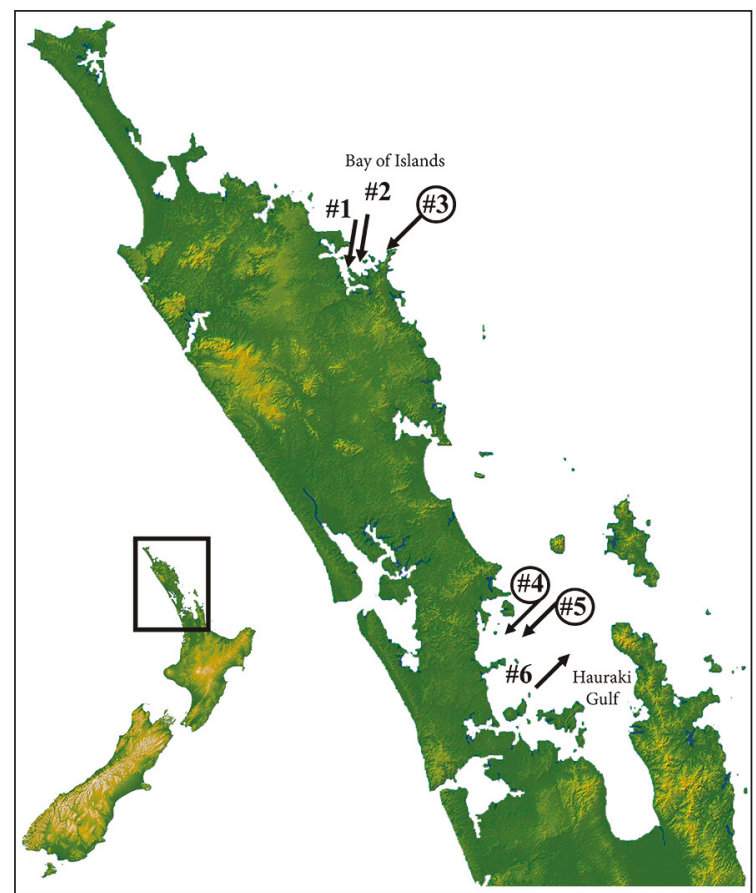

Figure 7. Sighting locations in Northland, New Zealand, for the female Pelagic ecotype orca (ID\# NZOP-005), (see Table 1 for dates and further details). She was documented with Xenobalanus at three locations \#3, \#4 \& \# 5, circled. The distance between \#3 at Cape Brett, Bay of Islands and \#4 in the Hauraki Gulf was $\sim 165 \mathrm{~km}$ (and 35 days apart), whilst the distance between \#4 and \#5 was $\sim 4.5 \mathrm{~km}$ and one day.

Another barnacle (labelled ' +1 ' in figure 15) has either become newly settled or it was of such a small size in August that it was not visible in the photograph and has since grown to be a size similar to its adjacent conspecifics. Although two other scenarios cannot be ruled out; (a) ' +1 ' may instead be barnacle A or; (b) both A and ' +1 ' are new recruits and have grown to this size in 36 days. Regardless, based on the proximity of these two Xenobalanus, at least one was not attached on 20150823. Therefore, four barnacles were attached, either sequentially or concurrently, at some point over the $\sim$ month-long period and, of those, two appear to have remained attached over the 36-day period.

After 20150927, NZOP-005 was not photographed again until 1,494 days later (i.e., 4 years, 1 month, 3 days) on 20191029 (record \#6, Table 1, Fig. 7). Despite the duration between sightings, she was documented only $\sim 23 \mathrm{~km}$ to the south of 
the 2015 sightings, again in the Hauraki Gulf. When she was photographed during the 2019 encounter there were no Xenobalanus on her dorsal fin (Fig. 6).

There was no seasonal trend to the sightings of NZOP-005 as she was documented in three Austral seasons (i.e., not summer, Table 1) and the sightings of the Xenobalanus were only four weeks apart. The sea surface water temperature ranged from 14$21{ }^{\circ} \mathrm{C}\left(14-16{ }^{\circ} \mathrm{C}\right.$ on the three days the Xenobalanus were documented) and depths from 18-43 m (25$40 \mathrm{~m}$ on days the Xenobalanus were documented) (Table 1).

\section{DISCUSSION}

\section{Pigmentation, rake marks \& cookie cutter shark bite marks}

Although 'open' saddle patches have been documented on NZ Coastal and Antarctic orca ecotypes in NZ waters (Visser, 2000; Visser \& Cooper, 2020 b), they are not a typical pigmentation pattern in these waters. Between 1992-1997, 52 individuals from the NZ Coastal orca population were photographed on both the left and right sides (Orca Research Trust, unpublished data) and 49 of those

\begin{tabular}{|c|c|c|c|c|c|c|c|}
\hline \begin{tabular}{|} 
Record \#, \\
Date \\
(yyyymmdd) \\
Austral \\
Season
\end{tabular} & $\begin{array}{l}\text { Geographic } \\
\text { Location }\end{array}$ & \begin{tabular}{|} 
Isistius sp. \\
bite \\
mark(s) \\
(left side)
\end{tabular} & $\begin{array}{l}\text { Xenobalanus } \\
\text { globicipitis } \\
\text { (number / loca- } \\
\text { tion on host) }\end{array}$ & $\begin{array}{l}\text { Water } \\
\text { Temp / } \\
\text { Depth }\end{array}$ & $\begin{array}{c}\text { Distance } \\
\text { (direct line } \\
\text { by sea from } \\
\text { previous } \\
\text { sighting) }\end{array}$ & $\begin{array}{c}\text { Duration } \\
\text { (since previous } \\
\text { sighting - includ- } \\
\text { ing end date) }\end{array}$ & Source \\
\hline $\begin{array}{c}\# 1 \\
20080818 \\
\text { Winter }\end{array}$ & $\begin{array}{c}\text { Tapeka, Bay of } \\
\text { Islands } \\
35^{\circ} 14^{\prime} \mathrm{S}, \\
174^{\circ} 07^{\prime} \mathrm{E}\end{array}$ & $\begin{array}{l}1, \text { spinal } \\
\text { ridge } \\
1, \text { lower } \\
\text { saddle }\end{array}$ & $\begin{array}{c}\text { Low resolution } \\
\text { image, not possible } \\
\text { to determine if } \\
\text { present (Fig. 4) }\end{array}$ & $\begin{array}{c}14.4^{\circ} \mathrm{C} \\
18 \mathrm{~m}\end{array}$ & $\mathrm{~N} / \mathrm{A}$ & $\mathrm{N} / \mathrm{A}$ & $\begin{array}{l}\text { Photographed } \\
\text { by Jochen R. } \\
\text { Zaeschmar }\end{array}$ \\
\hline $\begin{array}{c}\# 2 \\
20100325 \\
\text { Autumn }\end{array}$ & \begin{tabular}{|c|} 
South \& East of \\
the Black Rocks, \\
Bay of Islands \\
$35^{\circ} 13^{\prime} \mathrm{S}$, \\
$174^{\circ} 09^{\prime} \mathrm{E}$
\end{tabular} & $\begin{array}{l}1, \text { spinal } \\
\text { ridge } \\
1, \text { lower } \\
\text { saddle }\end{array}$ & 0 , on dorsal fin & $\begin{array}{l}21^{\circ} \mathrm{C} \\
35 \mathrm{~m}\end{array}$ & $\begin{array}{l}\sim 3.7 \mathrm{~km} \\
\text { (to the } \\
\text { north) }\end{array}$ & $\begin{array}{c}585 \text { days or; } \\
1 \text { year, } 7 \text { months, } \\
8 \text { days }\end{array}$ & $\begin{array}{c}\text { Photographed } \\
\text { by Jochen R. } \\
\text { Zaeschmar, } \\
\text { Dolphin Explore } \\
\text { (Tommy Hatwell) } \\
\text { Visser et al., (2010) }\end{array}$ \\
\hline $\begin{array}{c}\# 4 \\
20150926 \\
\text { Spring }\end{array}$ & \begin{tabular}{|c|} 
North of Whanga- \\
paraoa Peninsula, \\
Hauraki Gulf \\
$36^{\circ} 32^{\prime} \mathrm{S}$, \\
$174^{\circ} 49^{\prime} \mathrm{E}$ \\
\end{tabular} & $\begin{array}{l}1, \text { spinal } \\
\text { ridge } \\
1, \text { lower } \\
\text { saddle }\end{array}$ & $\begin{array}{c}\text { 3, near tip of dorsal } \\
\text { fin (Fig. 3) } \\
>14 \text {, L tail fluke } \\
>26 \text {, R tail fluke } \\
\text { (Fig. 8) }\end{array}$ & $\begin{array}{l}14^{\circ} \mathrm{C} \\
25 \mathrm{~m}\end{array}$ & $\begin{array}{l}\sim 165 \mathrm{~km} \\
\text { (to the } \\
\text { south) } \\
\text { (@1738 } \\
\text { hrs) }\end{array}$ & $\begin{array}{c}35 \text { days or; } \\
1 \text { month, } 4 \text { days }\end{array}$ & $\begin{array}{l}\text { Photographed by } \\
\text { INV \& HG }\end{array}$ \\
\hline $\begin{array}{c}\# 5 \\
20150927 \\
\text { Spring }\end{array}$ & $\begin{array}{l}\text { North East of } \\
\text { Whangaparaoa } \\
\text { Peninsula, } \\
\text { Hauraki Gulf } \\
36^{\circ} 32^{\prime} \text { 'S, } \\
174^{\circ} 52^{\prime} \text { 'E }\end{array}$ & $\begin{array}{l}1, \text { spinal } \\
\text { ridge } \\
1, \text { lower } \\
\text { saddle }\end{array}$ & $\begin{array}{c}3, \text { near tip of } \\
\text { dorsal fin } \\
>22, \mathrm{R} \text { pectoral fin } \\
>14, \mathrm{~L} \text { pectoral fin } \\
>26, \mathrm{R} \text { tail fluke } \\
>14, \mathrm{~L} \text { tail fluke } \\
\text { (total }>79) \\
\text { (Figs. } 2,3,9,11-13)\end{array}$ & $\begin{array}{l}14^{\circ} \mathrm{C} \\
30 \mathrm{~m}\end{array}$ & $\begin{array}{c}\sim 4.5 \mathrm{~km} \\
\text { (to the east) } \\
\text { (@0032 } \\
\text { hrs) }\end{array}$ & 1 day & $\begin{array}{l}\text { Photographed by } \\
\text { INV \& HG }\end{array}$ \\
\hline
\end{tabular}

Table 1. Sighting dates and locations of NZOP-005, a female Pelagic ecotype orca (Orcinus orca), noting records of cookie cutter shark (Isistius sp.) bite marks (on her left side as this was documented in all sightings) and pseudo-stalked barnacles (Xenobalanus globicipitis), as well as the distance and duration between sightings. She was documented six times over a period of 4,090 days (or 11 years, 2 months, 12 days). Austral Seasons; Spring = September, October, November; Summer = December, January, February; Autumn = March, April, May; Winter = June, July, August. (http://www.bom.gov.au/climate/ glossary/seasons.shtml). 
had symmetrical saddle patches, while only three had asymmetrical saddle patches (Mäkeläinen, 1999). NZOP-005, a NZ Pelagic ecotype, exhibits an 'open' left saddle patch, but her right is 'smooth' (following the definitions given in Sugarman, 1984 and Baird \& Stacey, 1988). Traditionally, orca identification catalogues tended to feature just the left side (e.g., see Bigg et al., 1987; Heise et al., 1991; Ford et al., 1994; Ford \& Ellis, 1999), however, more recently both sides are published in catalogues (e.g., Denkinger \& Alarcon, 2017) or only one side is published and the other is available within the database of the research project (e.g., Visser \& Cooper, 2020b and the Center for Whale Research as cited in Visser \& Mäkeläinen, 2000). To increase the probability of matching individuals, reducing mismatches and also minimising missed matches, as well as to document asymmetry in saddle patches, we recommend that photographs of both sides of individuals are collected.

The duration of visible rake marks on NZOP005 is the first indicating longevity of rake marks for over four years. Conspecifics rake marks on orca are a poorly reported phenomenon with most descriptions being of limited nature (e.g., see Scheffer, 1969; Lockyer, 1979; Hoyt, 1984; Ford et al.,
1994). There is only one publication that reports 'prolific' rake marks on free-ranging orca and those included extensive and numerous marks in parallel rows of three or four over much of the body of two male orca (Visser, 1998). The behavioural cause for those rake marks, although attributed to conspecifics, was not established, but aggression is rarely reported in free-ranging populations (Towers et al., 2018). Yet it is prevalent in captivity, where aggression has been linked to rake marks, which can also be extensive (e.g., see Figs. 16-18 in Visser (2012), where more than 90 attacks were recorded in 77 hours of observations). The causative behaviour behind the rake marks on NZOP-005's saddle patch is undeterminable as the event during which they were formed was not witnessed.

Cookie cutter shark bite marks are not commonly documented on the NZ Coastal orca population, with the first being recorded in 2007. That bite was visible for 1,158 days (or 3 years, 2 months and 1 day) (Dwyer \& Visser, 2011). The record for longevity of a cookie cutter bite mark being visible, is now held by NZOP-005 who exhibited two bite marks on 20080818 (i.e., on her spinal ridge and on her lower left saddle patch) which were still visible on 20191029 (i.e., 4,090 days (or 11 years, 2

\begin{tabular}{|c|c|c|c|c|c|c|c|c|c|c|}
\hline Region & Species & Date & $\begin{array}{c}\mathbf{R} \\
\text { fluke }\end{array}$ & $\begin{array}{c}\text { L } \\
\text { fluke }\end{array}$ & $\begin{array}{c}\mathbf{R} \\
\text { pectoral }\end{array}$ & $\begin{array}{c}\text { L } \\
\text { pectoral }\end{array}$ & $\begin{array}{c}\text { Dorsal } \\
\text { fin }\end{array}$ & Total* & $\begin{array}{c}\text { Source } \\
\text { Information }\end{array}$ & Source \\
\hline India & $\begin{array}{c}\text { Tursiops } \\
\text { truncatus }\end{array}$ & 19850128 & 8 & 4 & 1 & 1 & 0 & 14 & $\begin{array}{c}\text { page 197 (text), } \\
\text { page 198 (Fig. 1), } \\
\text { page 199 } \\
\text { (Table 1) }\end{array}$ & $\begin{array}{c}\text { Rajaguru \& } \\
\text { Shantha (1992) }\end{array}$ \\
\hline India & $\begin{array}{c}\text { Tursiops } \\
\text { truncatus }\end{array}$ & 19980329 & 4 & 0 & 0 & 0 & 0 & 4 & $\begin{array}{c}\text { page 879 (text), } \\
\text { page 880 (Fig. 2) }\end{array}$ & $\begin{array}{c}\text { Karuppiah et al., } \\
\text { (2004) }\end{array}$ \\
\hline $\begin{array}{c}\text { South } \\
\text { Africa }\end{array}$ & $\begin{array}{c}\text { Orcinus } \\
\text { orca }\end{array}$ & Not given & 5 & 2 & 9 & 5 & ND & 21 & page 266 (text) & Best (2007) \\
\hline $\begin{array}{c}\text { South } \\
\text { Africa }\end{array}$ & $\begin{array}{c}\text { Orcinus } \\
\text { orca }\end{array}$ & Not given & $>6$ & 2 & ND & ND & ND & 9 & Their Supl. Fig. \\
S2 & $\begin{array}{l}\text { Whitehead et al., } \\
(2014), \text { S2 photo } \\
\text { by Lloyd } \\
\text { Edwards }\end{array}$ \\
\hline $\begin{array}{c}\text { New } \\
\text { Zealand }\end{array}$ & $\begin{array}{c}\text { Orcinus } \\
\text { orca }\end{array}$ & 20150927 & 26 & 14 & 22 & 14 & $\begin{array}{c}3 \\
(+1) * *\end{array}$ & $\begin{array}{c}79 \\
(+1) * *\end{array}$ & Figs 2, 3, 6 \& 8 & This paper \\
\hline
\end{tabular}

Table 2. Comparison of Xenobalanus globicipitis attached on right (R) and (L) sides of cetaceans in the published literature ( $>70$ manuscripts were assessed for $\mathrm{R}$ and $\mathrm{L}$ details, however only four contained this type of data). Note; ND = Not documented, whereas ' 0 ' = documented as not present. * Numbers given by source, or total visible in photos, whilst also recognising that not all appendages may have been photographed/assessed. **between sightings, one Xenobalanus was shed and another $(+1)$ grew to a similar size as its adjacent conspecifics, so although there were only ever three documented at any one time, there were four documented on the dorsal fin over time (see figures 14 and 15 and text for details). 
months, 12 days) later). At that point she was also documented with a third cookie cutter bite mark in her left saddle patch. That mark had a distinctive dark ring of pigmentation around it, similar to one documented in Dwyer \& Visser (2011, their Fig. $5 b$ ), which was 150 days post an open-wound state, suggesting that the third bite mark on NZOP-005 may have been relatively recently healed.

\section{Xenobalanus globicipitis}

Kane et al. (2008) provided a review of published and unpublished accounts of Xenobalanus on 34 cetacean species in 24 regions, however it contained no records of Xenobalanus on any cetacean species in NZ waters. Although Kane et al. (2008) included Xenobalanus on orca (with an emphasis on the Eastern Tropical Pacific region), a number of new records in the regions of Australia, Brazil, Canadian Arctic, Canary Islands, Galápagos Islands, Gibraltar, Guatemala Basin, Japan, Mexico, Peru and South Africa have since become available (see introduction for citations). We now add NZ (this paper, Fig. 1) and note that this is the first record of Xenobalanus on any cetacean species in $\mathrm{NZ}$ waters.

The earliest records of Xenobalanus on orca, globally, come from the Mediterranean area, where two orca were captured six years apart, in 1896 and 1902 (Richard \& Neuville, 1897; Gruvel, 1920; Richard \& Neuville, 1936). Records have been sporadic in the area since; e.g., Foote et al. (2011) stated that in their 1971-2008 study "No Isistius wounds or Xenobalanus barnacles were seen on any individuals in more northerly waters [than the Canary Islands] including the Strait of Gibraltar." However, in contrast, the online catalogue of orca from the Strait of Gibraltar (CIRCE, 2020) includes a number of orca who have Xenobalanus on their dorsal fins and the dates those images were taken spans 2004-2013. A potential change in the distribution of Xenobalanus (or their hosts' dispersal/use of core areas) may have occurred multiple times in that area. Rappé \& Van Waerebeek (1988) stated that "it would appear that its [Xenobalanus] occurrence in the northeast Atlantic and Mediterranean is erratic, being separated by great lapses of time." Although early records are limited, an apparent trend of Xenobalanus being present in the late 1800 's and early 1900's, absent during the 1970's until approximately 2004, and present again more recently indicates support for this temporal distribution theory.

With respect to geographic distribution of orca from more contemporary times, they seasonally occupy the Strait of Gibraltar (e.g., see de Stephanis et al., 2008), whilst in the Mediterranean Sea they are considered 'visitors' (e.g., see Reeves \& Notarbartolo de Sciara, 2006) which may be influencing our knowledge of both the host and the barnacle in those regions. Changes in spatial distribution may also be occurring in other regions. The potential of long-range movements by orca in the Canadian Arctic has been speculated (Matthews et al., 2020), as Xenobalanus have only recently been documented on the dorsal fins of some individuals who may be travelling to warmer waters. It is recognized that the loss of Arctic sea ice is causing a change in the sightings of orca in the Canadian Arctic (Higdon $\&$ Ferguson, 2009) including their 'pulses of advancement' into areas they have not previously been documented. Alternatively, it could be the Xenobalanus barnacles which have a changed distribution. For example, human assisted dispersal of larvae could create a rapid increase of sightings in an area, as suggested by Siciliano et al. (2020), i.e., the possibility that the recent occurrence and subsequent infestations on cetaceans of Xenobalanus off Brazil, originated from the conveyance of their larvae in vessel ballast water.

Worldwide, most records of Xenobalanus are from tropical and temperate regions and the barnacle is thought to be a warm-water species (Rappé \& Van Waerebeek, 1988) based on the concentration of records given in Rajaguru \& Shantha (1992) and Kane et al. (2008). However, in subtropical eastern Australia, Orams \& Schuetze (1998) found that Xenobalanus presence on Tursiops truncatus, Montagu, 1821, was significantly less in summer (water temperatures of $24^{\circ} \mathrm{C}$ ) than when the water was $18^{\circ} \mathrm{C}$, indicating a thermal preference towards cooler temperatures. Over the last century the world has experienced an exponential rise in marine heatwaves affecting oceanic environments including shifts in marine species distribution (Oliver et al., 2018). In NZ, Pinkerton et al. (2019) report increasing sea surface temperatures "with average rates of warming between +1.2 and $+2.8^{\circ} \mathrm{C}$ per decade (mean of $+2.0{ }^{\circ} \mathrm{C}$ per decade)". However, future climate change scenarios indicate a potential de- 


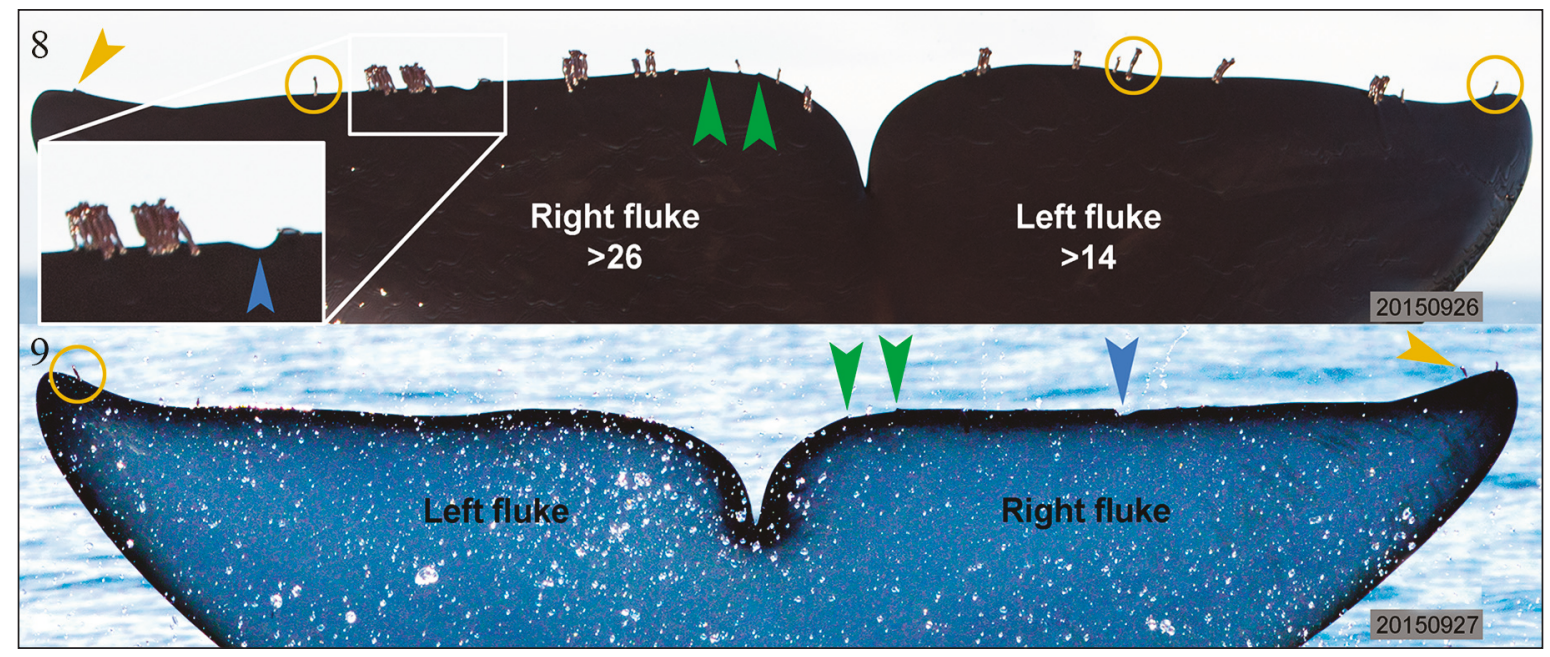

Figures 8, 9. On 20150926, the tail flukes of NZOP-005 were photographed for the first time (Fig. 8). There were at least 40 Xenobalanus ( $>26$ on her right fluke and $>14$ on her left fluke, see S-2 for details regarding numbers). The distribution along the trailing edge extended nearly the whole length of each fluke with some settled as singles or spread out (brown circles) and others clustered tightly together (Fig. 8 insert, Fig. 10 and S-2). The close clustering obscured some barnacles, therefore the number of individuals was likely higher than indicated. Dorsal views of tail flukes do not typically show barnacles attached to the ventral side, unless they are forced into view via centrifugal force (e.g., brown arrow at left of figure 8 and then at right in figure 9). The blue arrows indicate a rounded notch in her right fluke while the green arrows indicate a missing shallow area which had 'hard corners' (also see Fig. 10). Although figure 9 was taken a day later than figure 8 and appears to have a significantly lower number of barnacles, comparison of this topside (ventral) image to the underwater (dorsal surface) fluke image in figure 11 (also taken on 20150927) establishes that the barnacles were still present. Photographs by HG (top), INV (bottom)

crease in water temperature for some locations (Long \& Perrie, 2015). Rapid habitat change has been identified as putting all cirripedes at risk (Buckeridge, 2012) and as such, ocean thermal shifts and $\mathrm{pH}$ changes (e.g., ocean acidification) could be critical regarding Xenobalanus distribution, as they may be linked to growth and development, including mineral compositions of the shells as has been found for other barnacle species, e.g., Findlay et al. (2010) and Nardone et al. (2018). Although the pseudo-stalked Xenobalanus has reduced shells, there may still be implications for attachment to cetaceans, as the attachment plates are exposed above the epidermis of the host (Pugliese et al., 2012).

Certainly, the number of geographic regions where Xenobalanus have been documented has increased since the earlier reviews by Rajaguru \& Shantha (1992) and Kane et al. (2008) where ten regions were listed collectively between 1896 (Richard \& Neuville, 1897; Richard, 1936) and 2007 (Kane et al., 2008), i.e., in 111 years. We have now collated an additional 10 regions (including this paper) in the 13 years since (i.e., 2007-2020). To reconcile such an extreme difference, we speculate what some potential causative factors may be and recognise that they may not be mutually exclusive. Xenobalanus logically could have gone undocumented on their hosts, or; they could have been under-reported or; more recently observer bias (such as access to better cameras, as well as an increase in dedicated on-water research projects) may have resulted in more records, or; a change in distribution of the hosts and/or the barnacles may result in less or more sightings. Nevertheless, without longerterm databases and robust documentation of the presence of Xenobalanus we may not be able to ascertain the driving force(s) behind these new regional records.

While other publications have noted Xenobalanus on orca when discussing photo-identification of orca (e.g., Fertl et al., 1996; Olson \& Gerrodette, 2008; Pacheco et al., 2019), the duration that Xenobalanus remain on any individual host has not, to the best of our knowledge, been specifically documented. In Pacheco et al. (2019) a single adult 
male orca was documented moving between the Galápagos Islands, Mexico and Peru and he is described as having "between five to 10 coronulid barnacles (Xenobalanus globicipitis) attached" on his tail flukes. Two of the photographs in that publication (their Fig. 2), show Xenobalanus and it is possible to establish the potential dates and locations where the images were taken from the data in the text. The duration between any of the dates, as well as the distance between the two locations, would far exceed the duration/distances given herein. However, the images in Pacheco et al. (2019) are of such low resolution that it is impossible to determine if the Xenobalanus are in the same location on the tail flukes and, therefore, if they could potentially be the same individual barnacles or if they were subsequently recruited. Therefore, attachment duration cannot be determined from the data in that publication.

On NZOP-005, barnacle ' +1 ' (Fig. 15) was not visible in August and yet it was a similar size to its conspecifics (barnacles A \& B) 36 days later, suggesting a fast growth rate. Toth-Brown 2007, states, that "These [Xenobalanus] larvae develop and settle once an appropriate host is found, and life cycles of 5-6 months have been reported (Van Waerebeek et al., 1993; Fertl, 2002)". However, if the biological definition of the term "life cycle" is used, this

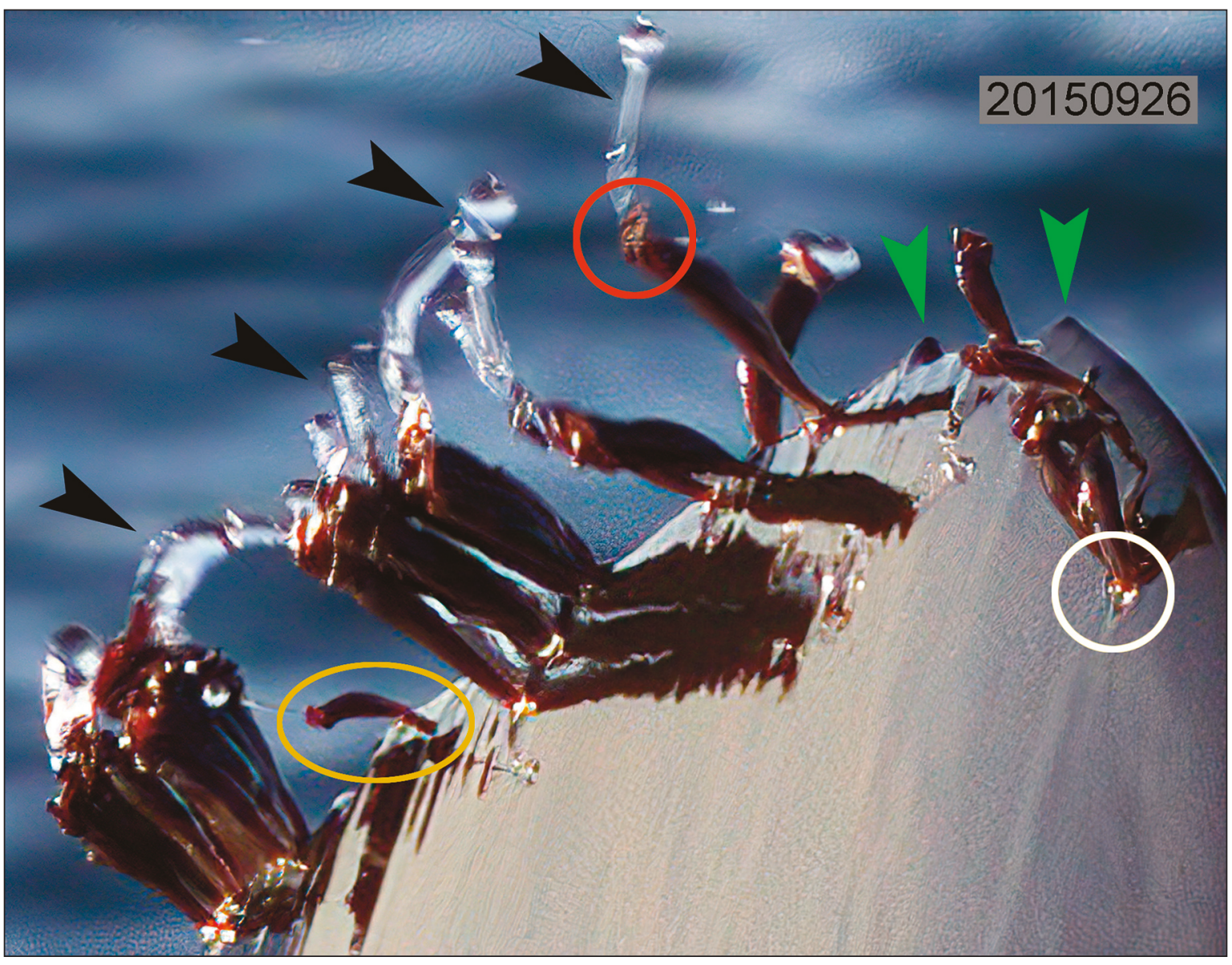

Figure 10. Close clustering obscures some barnacles, while others (e.g., a single barnacle circled in brown) are attached to the ventral side of the tail flukes and only become visible as the fluke is moved. Pale creamy-white basal plates can be seen in two Xenobalanus (white circle). At least one of the barnacles has its cirri extended beyond the 'hood' of the body (red circle). Due to the centrifugal force from the motion of the hosts' tail flukes, water previously adhering to the barnacles, was flung outwards (black arrows). The green arrows indicate a missing shallow area in the trailing edge of the tail fluke which had 'hard corners' (also see Figs. 8, 9). Photo post-processed using TopazLabs Stabilize AI and Gigapixel AI software. Photograph by INV. 
implies that the barnacles live for 5-6 months. Fertl (2002: 75) actually makes no reference to this timeline other than to say "The breeding season of barnacles that cling to whales is synchronous with that of the whales' breeding season." where as Van Waerebeek et al. (1993: 167) state "The clear sixmonth phase in peak occurrence suggests seasonally controlled swarming of nauplius larvae". In both instances these authors are referring to the breeding cycle, not the life cycle. Currently, the lifecycle (hatching to death) is unknown for this species.

Alternatively, although the barnacles labelled A and $\mathrm{B}$ are presumed to have remained attached during the 36-day period, it can't be ruled out that they may have been replaced by others in exactly the same locations on the dorsal fin. Toth-Brown \& Hohn (2007) investigated Xenobalanus on 176 bottlenose dolphins (Tursiops truncatus Montagu 1821). They resighted some individual's multiple times in one or two years but they noted that "the position of certain barnacles on the dorsal fin was slightly different from year to year (Fig. 3). This in- dicates that among years at least some barnacles had fallen off and were replaced with new ones." and as such they too provide no duration data for any of the Xenobalanus.

The Xenobalanus we describe on NZOP-005 were typical with regards to their distribution on the body of the orca e.g., Fertl \& Newman (2018) state "Xenobalanus globicipitus [sic], while worldwide in distribution, are almost always found on the trailing edges of the dorsal and pectoral fins and on the flukes of ... cetacean species", although Xenobalanus are also occasionally located in other zones of the body of orca, such as at the base of the dorsal fin (Siciliano et al., 2020). Although Whitehead et al. (2014: fig. 1) provide images of orca off the coast of South Africa, it is not clear how many orca are depicted in the three photographs. Regardless, the distribution of the Xenobalanus on the dorsal fin and right pectoral fin for these South African animal(s) is similar to those on NZOP-005.

Carrillo et al. (2015) looked in detail at the distribution of Xenobalanus on 95 striped dolphins and found that they were more likely to be on the tail

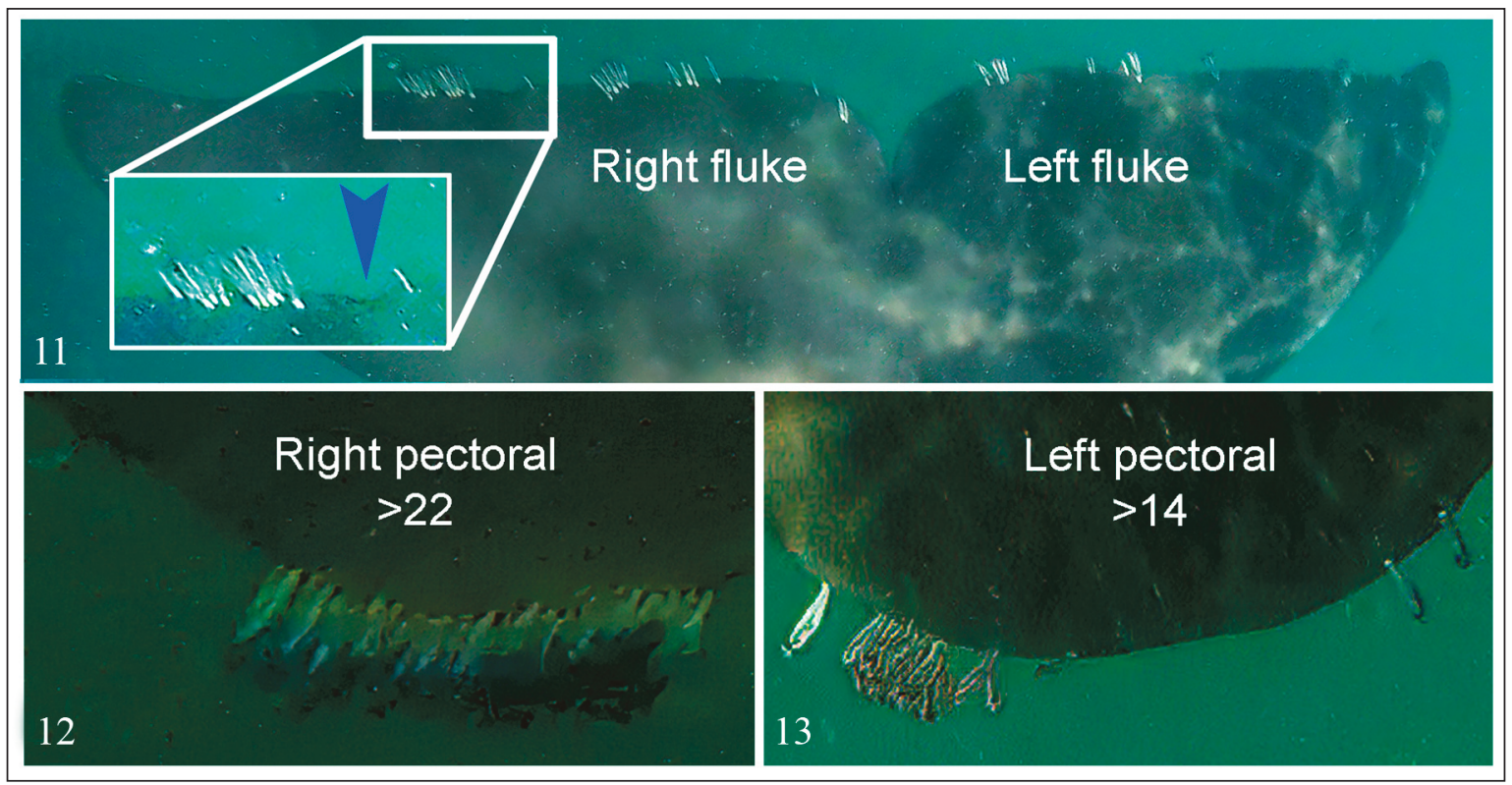

Figures 11-13. Frame grabs from underwater video taken on 20150927, show the Xenobalanus globicipitis on the tail flukes (Fig. 11), as well as the trailing edges of the pectoral fins (Figs. 12,13) of the female orca NZOP-005. The barnacles appear lighter in colour as a result of the water filtering out visible red light (see text for details). This artifact is apparent when comparing the underwater images to the topside image of the flukes in figure 10, where the darker colour of the barnacles is visible. The approximate number of barnacles on the pectoral fins is indicated on the images (see $\mathrm{S}-2$ for details). Frames from the video were post-processed using TopazLabs Stabilize AI and Gigapixel AI software. Insert is adjusted (contrast \& brightness) to show notch. Images by HG and INV. 
flukes than on the pectoral fins, with the lowest prevalence on the dorsal fins. When found on the tail flukes of the striped dolphins, the Xenobalanus were more likely to be on the dorsal surface than the ventral and more towards the centre of the tail than the distal ends. On NZOP-005 the lowest prevalence was also on her dorsal fin, followed by an increasing number on her pectoral fins and her tail flukes. And, like the dolphins, when Xenobalanus were on the tail flukes they were mostly on the dorsal surface, although they were spread over the whole span.

Although Carrillo et al. (2015) provide a very comprehensive analysis of the settlement patterns of Xenobalanus, they did not provide data on the prevalence of the barnacle's distribution on the right and left appendages. Likewise, Moreno-Colom et al. (2019) provide a detailed assessment of distribution of Xenobalanus on the tail flukes of dolphins paying particular attention to the dorsal and ventral surfaces, yet they provide no right and left side numbers. Barnacle species are often gregarious (Knight-Jones, 1953), including Xenobalanus who have been shown to aggregate and cluster together (i.e., the nearest neighbour distribution is not random, Moreno-Colom et al., 2019). In theory, barnacles settling onto the pectoral fins or tail flukes of a cetacean should be relatively evenly distributed on the right and left sides, if no other factors were at play. One might speculate that the higher number of Xenobalanus on the right side of the orca (see details for the three orca hosts in Table 2), may be a facet of favouring one side over the other.

The discrepancy of distribution between the number of Xenobalanus on the right and the left appendages of NZOP-005 may be typical for orca, as the (albeit limited) laterally distinguished data on Xenobalanus distribution on cetaceans, shows a similar trend of higher numbers on the right side (Table 2). At least eight species of cetaceans favour their right side for foraging (e.g., see Kaplan et al. (2019) and references therein). In contrast to that trend is one study on Indo-Pacific bottlenose dolphins (Tursiops aduncus Ehrenberg, 1832) off Japan which showed significant left-side bias when using a flipper for rubbing a conspecific (Sakai M. et al., 2006).

At least some orca show lateral asymmetry when using their pectoral fins and typically favour using their right side (Giljova et al., 2016), they show lateralization for the spatial relationships between mother and infant which also favours the right side (Karenina et al., 2013) and during lunging (when feeding) the orca again show a favouring of the right side (Karenina et al., 2015). Such lateralization likely creates differential water flows over the appendages, potentially influencing settlement and/or feeding and/or growth of Xenobalanus.

Although little is known about the early life-history stages of Xenobalanus, water flow has been described as having an impact on settlement success of Xenobalanus (Wethey et al., 1988; Carrillo et al., 2015; Moreno-Colom et al., 2019) and the "larval settlement on marine mammals can be considered an extreme lifestyle as the hosts are fast-swimming and migrate over great distances in the open oceans, but also because they slough the outermost, non-living cell layer of the epidermis up to several times a day" (Dreyer et al., 2020).

The number of Xenobalanus documented on NZOP-005 $(n=>79)$, were more than 3.5 times higher than any other orca; $(n=22)$ in Canadian Arctic; $(n=21)$ in South Africa. Yet the NZ Xenobalanus were also clearly transitory in nature (i.e., not present in 2010 and 2019 but present between, in 2015). With so few datapoints during the $11+$ years it is not possible to know the full duration of attachment and what influences recruitment and/or separation from the host. One possibility is water temperature, as Dreyer et al. (2020) hatched Xenobalanus larvae at $28^{\circ} \mathrm{C}$ and grew them to the cyprid stage in approximately eight days. NZOP-005 was not documented in summer and the sea surface water temperatures, when she was hosting Xenobalanus, were $14{ }^{\circ} \mathrm{C}-$ $16.5^{\circ} \mathrm{C}$ (Table 1). Van Waerebeek et al. (1993) noted a seasonal trend in the incidence rates of Xenobalanus on dusky dolphins (Lagenorhynchus obscurus Gray, 1828), from Peru, where August, September and October showed a downward trend, with the latter two being significantly lower than the peak months of May-July. They attributed these trends to a six-month phase of "seasonally controlled swarming nauplius larvae". In NZ, the apparent settlement and rapid growth of barnacle ' +1 ' on an orca between August and September, when the water was relatively cold, is suggestive that at least some settlement occurred and/or criteria for growth of Xenobalanus was met during the winter-spring seasons. And, although no measurements of the Xenobalanus were possible, when compared to the literature, the relative size and the morphology of most of the Xenobalanus on NZOP-005 suggests that they were near sexual 


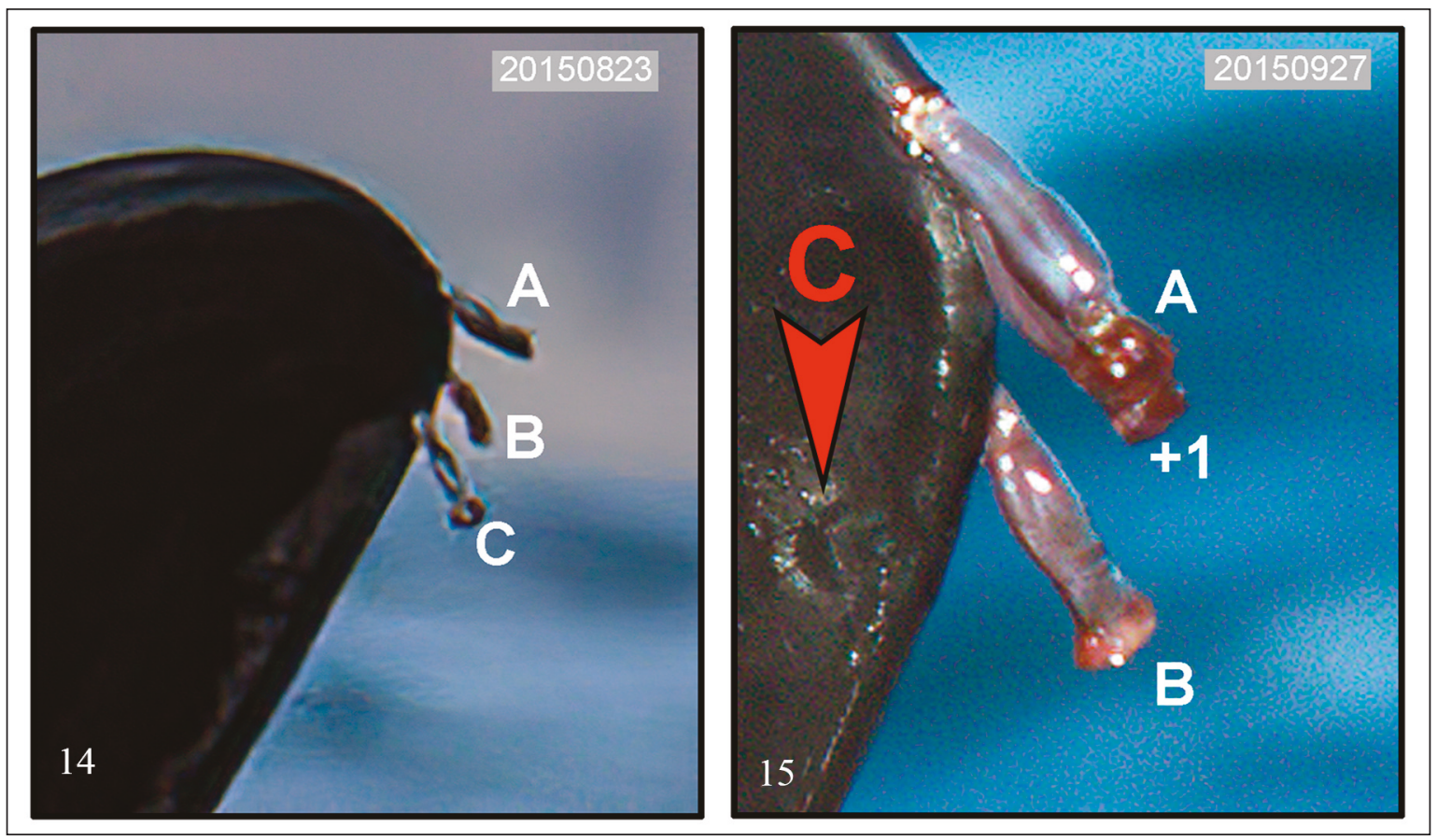

Figures 14,15 . The left side of the dorsal fin of NZOP-005, 36 days apart as indicated by the dates in yyyymmdd format on figures 14,15 . In figure 14, the three barnacles are approximately equidistant from each other. In figure 15, what is presumed to be barnacle A is attached on the edge of the dorsal fin, between the left and right sides, with another barnacle ' +1 ' tucked in directly under it (although it cannot be ruled out that this may instead be barnacle A). Barnacle B is not attached to the edge, but is rather on the right side of the dorsal fin. Barnacle $\mathrm{C}$ is clearly visible in figure 14 and its attachment point is on the left side of the fin. However, in figure 15 barnacle " $\mathrm{C}$ ' is no longer present and instead, a scar remains (arrow). Although it is not possible to ascertain which of the two upper-most barnacles in image Fig. 15 corresponds to barnacle A, it is clear that an additional (similar sized barnacle) is now present. The lighter colouring of the barnacles in Fig. 15, particularly when compared to those in figure 7, is likely an artifact of the light conditions at the moment the barnacles were photographed. Both photos were post-processed using TopazLabs Stabilize AI and Gigapixel AI software. Photographs by HG (14) and INV (15).

maturity or possibly adults (although there were some smaller (in length and girth) individuals present as well, see Figs. 8, 10). Given that the Xenobalanus appeared to be semi- to fully mature when they were first photographed on 20150823, it is logical that they would have been attached to the orca prior to this date, therefore the 36 days documented between these two events is the minimum duration that the barnacles were attached.

\section{CONCLUSIONS}

Although the evidence presented herein is derived from just one female Pelagic ecotype orca, the limited information is compelling. The long-term visibility of the rake marks on NZOP-005 helps confirm them as a valuable tool in identifying indi- viduals, but it would be of benefit to have more data on their provenance in terms of the social/aggression interactions of conspecifics or inter-ecotype encounters.

The duration of the cookie cutter shark bite marks for more than 11 years gives weight to them being used as identification marks for individual recognition as well as biological tags for long-term periods and for distinguishing between ecotypes.

This first documentation specific to the duration (and colonisation/or growth) of the barnacle Xenobalanus globicipitis provides us with a baseline, but it also clearly illustrates a gap in our knowledge about the longevity of Xenobalanus and the driving forces behind their recruitment onto (and duration on) orca and what triggers their displacement. Furthermore, it also highlights that the use of Xenobalanus as population markers should be ap- 
plied in a cautionary manner and where possible used in combination with other population indicators/markers (such as behaviour, pigmentation, cookie cutter shark bite marks etc). If used for individual identification of any cetacean, Xenobalanus should be well documented by photographs/video to ensure that their numbers are accurately verified, as well as to monitor the potentially transitional nature of the barnacles over time.

Given the 'loss' of barnacle $\mathrm{C}$ and the addition of barnacle ' +1 ', using Xenobalanus for individual identification may be best suited to consecutive days/weeks where resightings are frequent. A similar recommendation was made, based on the seasonal occurrence of the barnacle on dusky dolphins, by Van Waerebeek et al. (1993) who suggested they "can serve as a sensitive ecological marker on a small temporal scale, i.e. months...". Longer-term monitoring of Xenobalanus will also help establish how robust they are as biological tags, including potential changes in distribution of the barnacles themselves (Siciliano et al., 2020).

Regardless, as is so often the case in the field of marine mammal biology (and in this instance also Xenobalanus), further documentation and reporting of similar scenarios, anomalies and even common place events, will help us to better understand the complexities of these species. For example, data regarding cookie cutter shark bite marks, which are rare on some ecotypes and common on others (Dwyer \& Visser, 2011; Visser \& Cooper, 2020b, 2020a), may help better define the ecotypes and their distribution. If bite marks appear more prevalently on an ecotype when they were previously uncommon, this may indicate a shift in the orca's habitat use (or that of Isistius sp.). As such, we encourage researchers to publish sightings of cookie cutter shark bite marks (and Xenobalanus), including historic data which could also help establish long-term trends, such as seen in here for the cookie cutter shark bite mark, or establish range extensions, such as seen here for the Xenobalanus.

With the consequences of climate change already influencing orca (Matthews et al., 2020), as well as other species of cetaceans (MacLeod et al., 2005; MacLeod, 2009), long-term impacts are likely and biological tags may be early indicators that changes are occurring. We therefore encourage management authorities to include in their action plans monitoring of both of these biological tags (as well as other potential markers), not only in field research, but also when cetaceans strand/die. The limited published data on these two indicator species illustrates that all too often they are perhaps overlooked or not considered of value.

Additionally, when implementing action plans, management authorities should ensure they consider climate change and prioritise aspects that can have conservation benefits for cetaceans, given the dynamic climate framework and the consequences cetaceans will face from its impacts.

We also strongly promote the recognition of various orca ecotypes as separate stocks. These will require separate management plans as has been done for Bigg's (Transient) (DFO, 2007), Offshore (DFO, 2009) and Resident ecotypes (DFO, 2017) in Canada. Given that we can already differentiate between a number of orca ecotypes by using features such as the biological tags described herein, it would be remiss of management authorities to not conduct due diligence and create separate plans, as these could have real-world consequences for the animals in question. At the extreme, if appropriate management protocols are not implemented expeditiously, an orca ecotype, particularly one with a small population size, could go extinct before it was even properly recognised.

\section{SUPPLEMENTAL MATERIAL}

S-1. Xenobalanus in manuscripts from Richard \& Neuville (1896), Gruvel (1920), Richard (1936) and Richard \& Neuville (1936), with discrepancies in citations of these records.

S-2. Details and counts of Xenobalanus for each appendage of orca NZOP-005.

\section{ACKNOWLEDGEMENTS}

Thank you to Jochen R. Zaeschmar, Dolphin Explore (Tommy Hatwell) \& Auckland Whale and Dolphin Safari (Andy Light, Sam Peate and Sarah Tranmer) for their additional photographs and sighting data of NZOP-005; to Genevieve Douyon, Claire Guillaume, Dagmar Fertl and Roselle Rose for their assistance with sourcing references and translations; to Silvia and Walter Streit for their 
sponsorship of camera equipment; to Terry $\mathrm{M}$. Hardie who provided cloud storage for all the data and facilitated file sharing and to Uber Ultra-fast Broadband for their uplinks \& internet service. Ben Noll, NIWA meteorologist, kindly supplied sea surface temperature data. Dr's Emma Foster and Krista Hupman reviewed the manuscript; we thank them for their suggestions which improved it. A special thank you to Miss Jackie C in Amsterdam who provided financial support for the research and publication charges. The authors also wish to thank the Orca Research Trust who provided logistical support and all the citizen scientists who contribute sightings and images of orca in New Zealand waters.

\section{REFERENCES}

Aznar F.J., Perdiguero D., Pérez del Olmo A., Repullés A., Agustí C. \& Raga J.A., 2005. Changes in epizoic crustacean infestations during cetacean die-offs: the mass mortality of Mediterranean striped dolphins Stenella coeruleoalba revisited. Diseases of Aquatic Organisms, 67: 239-247. https://doi.org/10.3354/dao067239

Baird R.W. \& Stacey P.J., 1988. Variation in saddle patch pigmentation in populations of killer whales (Orcinus orca) from British Columbia, Alaska, and Washington State. Canadian Journal of Zoology, 66: 25822585.

Bane G.W. \& Zullo V.A., 1980. Observations on a stranded goosebeaked whale (Ziphius cavirostris, $\mathrm{Cu}$ vier 1823) and its ectocommensal barnacles (Xenobalanus globicipitis). The Journal of the Elisha Mitchell Scientific Society, 96: 1-3.

Best P.B., 2007. Whales and Dolphins of the Southern African Subregion. Cambridge University Press, $352 \mathrm{pp}$.

Bigg M.A., Ellis G.M., Ford J.K.B. \& Balcomb K.C., 1987. Killer whales: A study of their identification, genealogy and natural history in British Columbia and Washington State. Phantom Press and Publishers, Nanaimo, B.C., 79 pp.

Black N.A., Schulman-Janiger A., Ternullo R.L. \& Guerero-Ruiz M., 1997. Killer whales of California and western Mexico; A catalog of photo-identified individuals. La Jolla, California. NOAA Technical Memorandum No.: Report No. NOAA-TM-NMFSSWFSC-2467, 174 pp.

Buckeridge J.S., 2012. Opportunism and the resilience of barnacles (Cirripedia: Thoracica) to environmental change. Integrative Zoology, 7: 137-146. https://doi. org/10.1111/j.1749-4877.2012.00286.x
Carrillo J.M., Overstreet R.M., Raga J.A. \& Aznar F.J., 2015. Living on the edge: Settlement patterns by the symbiotic barnacle Xenobalanus globicipitis on small cetaceans. PLoS ONE. 10: 1-15. https://doi.org/10. 1371/journal.pone.0127367 e0127367.

CIRCE, 2020. Orcas Estrecho. Catálogo de orcas del Sur peninsular. (last accessed $20201205 \mathrm{https}: / / \mathrm{www}$. flickr.com/photos/cetidmed/sets/721576375580803 85/).

Cortés Peña D., 2019. Orca at Chañaral de aceituno, Freirina, Atacama region, Chile. Facebook. https://www. facebook.com/groups/CetalFauna/permalink/206670 2686783266. (archived at https://perma.cc/9U8RE67Z)

Darwin C., 1854. A monograph on the sub-class Cirripedia with figures of all the species. The Balanidae (or sessile Cirripedes); The Verrucidae etc., etc., etc.,. Ray Society, London, 684 pp.

de Stephanis R., Cornulier T., Verborgh P., Sierra J.S., Pérez Gimeno N. \& Guinet C., 2008. Summer spatial distribution of cetaceans in the Strait of Gibraltar in relation to the oceanographic context. Marine Ecology Progress Series, 353: 275-288. https://doi.org/ 10.3354/meps07164

Denkinger J. \& Alarcon D., 2017. Orcas of the Galápagos Islands. CETACEA Project. 1-20 pp.

DFO, 2007. Recovery strategy for the Transient killer whale (Orcinus orca) in Canada. Species at Risk Act Recovery Strategy Series. Vancouver: Department of Fisheries and Oceans Canada. p. vi +46.

DFO, 2009. Management plan for the Offshore Killer whale (Orcinus orca) in Canada. Species at Risk Act Recovery Strategy Series. Nanaimo: Department of Fisheries and Oceans Canada. p. v + 1-49.

DFO, 2017. Action Plan for the Northern and Southern Resident Killer Whale (Orcinus orca) in Canada. Species at Risk Act Action Plan Series. Ottawa: Department of Fisheries and Oceans Canada. p. v $+1-$ 33.

Donnelly D., McInnes J.D., Morrice M. \& Andrews C., 2018. Killer whales of Eastern Australia. Killer Whales Australia, 54 pp.

Dreyer N., Zardus J.D., Høeg J.T., Olesen J., Yu M.-C. \& Chan B.K.K., 2020. How whale and dolphin barnacles attach to their hosts and the paradox of remarkably versatile attachment structures in cypris larvae. Organisms Diversity \& Evolution, 1-17. https://doi.org/10.1007/s13127-020-00434-3

Dwyer S.L. \& Visser I.N., 2011. Cookie cutter shark (Isistius sp.) bites on cetaceans, with particular reference to killer whales (orca) (Orcinus orca). Aquatic Mammals, 37: 111-138. https://doi.org/10.1578/AM. 37.2.2011.111

Fertl D.C., Acevedo-Gutiérrez A. \& Darby F.L., 1996. A report of killer whales (Orcinus orca) feeding on a 
carcharhinid shark in Costa Rica. Marine Mammal Science, 12: 606-611. https://doi.org/10.1111/j.17487692.1996.tb00075.x

Fertl D.C. \& Newman W.A., 2018. Barnacles. In: Perrin W. F., Würsig B. \& Thewissen J.G.M., Editors. Encyclopedia of marine mammals. Academic Press, San Diego, 75-78.

Findlay H.S., Kendall M.A., Spicer J.I. \& Widdicombe S., 2010. Relative influences of ocean acidification and temperature on intertidal barnacle post-larvae at the northern edge of their geographic distribution. Estuarine, Coastal and Shelf Science, 86: 675-682. https://doi.org/10.1016/j.ecss.2009.11.036

Foote A.D., Vilstrup J.T., de Stephanis R., Verborgh P., Able Nielsen S.C., Deaville R., Kleivane L., Martín V., Miller P.J.O., Ølien N., Pérez-Gil M., Rasmussen M., Reid R.J., Robertson K.M., Rogan E., Similä T., Tejedor M.L., Vester H., Víkingson G.A., Willerslev E., Gilbert M.T.P. \& Piertney S.B., 2011. Genetic differentiation among North Atlantic killer whale populations. Molecular Ecology, 20: 629-641. https:// doi.org/10.1111/j.1365-294X.2010.04957.x

Ford J.K.B. \& Ellis G.M., 1999. Transients: Mammalhunting killer whales. University of British Columbia Press, Vancouver, 96 pp.

Ford J.K.B. \& Ellis G.M., 2014. You are what you eat: Foraging specializations and their influence on the social organization and behavior of killer whales. In: Juichi Y. \& Karczmarski L., Editors. Primates and Cetaceans: Field Research and Conservation of Complex Mammalian Societies. Springer Japan, 7598.

Ford J.K.B., Ellis G.M. \& Balcomb K.C., 1994. Killer whales: The natural history and genealogy of $\mathrm{OrCi}$ nus orca in British Columbia and Washington State. University of British Columbia Press, Vancouver, $102 \mathrm{pp}$.

Fraija-Fernández N., Hernández-Hortelano A., AhuirBaraja A.E., Raga J.A. \& Aznar F.J., 2018. Taxonomic status and epidemiology of the mesoparasitic copepod Pennella balaenoptera in cetaceans from the western Mediterranean. Diseases of Aquatic Organisms, 128: 249-258. https://doi.org/10.3354/dao03226

Giljova A.N., Karenina K.A., Ivkovich T.V. \& Malashichev Y.B., 2016. Asymmetry of pectoral flipper use in the orca Orcinus orca (Linnaeus, 1758) from the Avachinskii Bay (Eastern Kamchatka). Russian Journal of Marine Biology, 42: 196-198. https://doi.org/10.1134/S1063074016020048

Gruvel J.A., 1920. Cirrhipedes provenant des campagnes scientifiques de S.A.S.le Prince de Monaco (18851913). In: Résultas des Campagnes Scientifiques accomplies sur son yacht par Albert ler, Prince Souverain de Monaco. Monaco, 1-88 pp.

Guerrero-Ruiz M.J. \& Urbán J.R. 2000. First report of remoras on two killer whales (Orcinus orca) in the Gulf of California, Mexico. Aquatic Mammals, 26: 148-150.

Hartny-Mills L., 2015. Site fidelity, social structure and spatial distribution of short-finned pilot whales, Globicephala macrorhynchus, off the South West coast of Tenerife. University of Portsmouth, 220 pp.

Heise K., Ellis G.M. \& Matkin C., 1991. A catalogue of Prince William Sound killer whales. North Gulf Oceanic Society, 51 pp.

Higdon J.W. \& Ferguson S.H., 2009. Loss of Arctic sea ice causing punctuated change in sightings of killer whales (Orcinus orca) over the past century. Ecological Applications, 19: 1365-1375. https://doi.org/10. 1890/07-1941.1

Hoyt E., 1984. Orca: The whale called killer. 3rd ed. Camden House Publishing Ltd, Ontario, 291 pp.

Kane E.A., Olson P.A., Gerodette T. \& Fiedler P.C., 2008. Prevalence of the commensal barnacle Xenobalanus globicipitis on cetacean species in the eastern tropical Pacific Ocean, and review of global occurrence. Fishery Bulletin, 106: 395-404.

Kaplan D.J., Goodrich S.Y., Melillo-Sweeting K. \& Reiss D., 2019. Behavioural laterality in foraging bottlenose dolphins (Tursiops truncatus). Royal Society Open Science, 6: 1-8 (e190929). https://doi.org/10. 1098/rsos.190929

Karenina K.A., Giljova A.N., Ivkovich T.V., Burdin A.M. \& Malashichev Y.B., 2013. Lateralization of spatial relationships between wild mother and infant orcas, Orcinus orca. Animal Behavior, 86: 1225-1231. https://doi.org/10.1016/j.anbehav.2013.09.025

Karenina K.A., Giljova A.N., Ivkovich T.V. \& Malashichev Y.B., 2015. Evidence for the perceptual origin of right-sided feeding biases in cetaceans. Animal Cognition, 19: 239-243. https://doi.org/10.1007/ s10071-015-0899-4

Karuppiah S., Subramanian A. \& Obbard J.P., 2004. The barnacle, Xenobalanus globicipitis (Cirripedia, Coronulidae), attached to the bottle-nosed dolphin, Tursiops truncatus (Mammaila, Cetacea) on the Southeastern coast of India. Crustaceana, 77: 879882. https://www.jstor.org/stable/20105767

Knight-Jones E.W., 1953. Laboratory experiments on gregariousness during setting in Balanus balanoides and other barnacles. Journal of Experimental Biology, 30: 584-598.

Lockyer C., 1979. Response of orcas to tagging. Carnivore, 2: 19-21.

Long Z. \& Perrie W., 2015. Scenario changes of Atlantic water in the Arctic Ocean. Journal of Climate, 28: 5523-5548. https://doi.org/10.1175/JCLI-D-14-005 22.1

MacLeod C.D., 2009. Global climate change, range changes and potential implications for the conservation of marine cetaceans: a review and synthesis. En- 
dangered Species Research, 7: 125-136. https://doi. org/10.3354/esr00197

MacLeod C.D., Bannon S.M., Pierce G., Schweder C., Laearmonth J.A., Herman J.S. \& Reid R.J., 2005. Climate change and the cetacean community of north-west Scotland. Biological Conservation, 124: 477-483. https://doi.org/10.3354/esr00197

Mäkeläinen P., 1999. Geographical variation in killer whale saddle patch and eye patch shape, Masters Thesis. Helsinki, Finland: University of Helsinki, 45 pp.

Mäkeläinen P., van Ginneken A.M. \& Pietiäinen H., 2013. Fluctuating asymmetry in the saddle patch shape of the Pacific Ocean killer whale (Orcinus orca) populations. Annales Zoologici Fennici, 50: 347-355. https://www.jstor.org/stable/23737213

Matthews C.J.D., Ghazal M., Lefort K.J. \& Inaurak E., 2020. Epizoic barnacles on Arctic killer whales indicate residency in warm waters. Marine Mammal Science, 1-5. https://doi.org/10.1111/mms. 12674

Moreno-Colom P., Ten S., Raga J.A. \& Aznar F.J., 2019. Spatial distribution and aggregation of Xenobalanus globicipitis on the flukes of striped dolphins, Stenella coeruleoalba: An indicator of host hydrodynamics? Marine Mammal Science, 1-18. https://doi.org/10. 1111/mms. 12691

Nardone J.A., Patel S., Siegel K.R., Tedesco D., McNicholl C., O’Malley J., Herrick J., Metzler R.A., Orihuela B., Rittschof D. \& Dickinson G.H., 2018. Assessing the impacts of ocean acidification on adhesion and shell formation in the barnacle Amphibalanus amphitrite. Frontiers in Marine Science, 5: 1-13 (e369). https://doi.org/10.3389/fmars.2018.00369

Nilsson-Cantell C.A., 1930. Thoracic cirripedes collected in 1925-1927. Discovery Reports, 2: 223-260.

Oliver E., Donat M., Burrows M., Moore P., Smale D., Alexander L., Benthuysen J., Feng M., Gupta A., Hobday A., Nolbrook N., Perkins-Kirkpatrick S., Scannell H., Straub S. \& Wernbrg T., 2018. Longer and more frequent marine heatwaves over the past century. Nature Conmmunications, 9: 1-12 (e1324). https://doi.org/10.1038/s41467-018-03732-9

Olson P.A. \& Gerrodette T., 2008. Killer Whales of the Eastern Tropical Pacific: A Catalog of Photo-Identified Individuals. La Jolla, California, USA, NOAA Technical Memorandum, National Oceanic and Atmospheric Administration, National Marine Fisheries Service, Southwest Fisheries Science Center, 120 pp.

Orams M.B. \& Schuetze C., 1998. Seasonal and age/size-related occurrence of a barnacle (Xenobalanus globicipitis) on bottlenose dolphins (Tursiops truncatus). Marine Mammal Science, 1: 186-189. https://doi. org/10.1111/j.1748-7692.1998.tb00706.x

Pacheco A.S., Castro C., Carnero-Hauman R., Villagra D., Pinilla S., Denkinger J., Palacios-Alfaro J.D.,
Sánchez Godinez C., Conzález-Rueluas R., Silva S., Alcorta B. \& Urbán R J., 2019. Sightings of an adult male killer whale match humpback whale breeding seasons in both hemispheres in the Eastern Tropical Pacific. Aquatic Mammals, 45: 320-326. https://doi. org/10.1578/AM.45.3.2019.320

Pinkerton M., Sutton P.J.H. \& Wood S., 2019. Satellite indicators of phytoplankton and ocean surface temperature for New Zealand. NIWA Client Report 2018180WN. Prepared for the Ministry for the Environment. Wellington, New Zealand. Wellington, New Zealand: NIWA, $87 \mathrm{pp}$.

Pitman R.L., Fearnbach H., LeDuc R., Gilpatrick J.W.J., Ford J.K.B. \& Ballance L.T., 2007. Killer whales preying on a blue whale calf on the Costa Rica dome: genetics, morphometrics, vocalisations and composition of the group. Journal of Cetacean Research and Management, 9: 151-157.

Pugliese M.C., Anne B.S. \& Fish F.E., 2012. Barnacle bonding: Morphology of attachment of Xenobalanus globicipitis to its host Tursiops truncatus. Journal of Morphology, 273: 453-459. https://doi.org/10.1002/ jmor.20006

Rajaguru A. \& Shantha G., 1992. Association between the sessile barnacle Xenobalanus globicipitis (Coronulidae) and the bottlenose dolphin Tursiops truncatus (Delphinidae) from the Bay of Bengal, India, with a summary of previous records from cetaceans. Fisheries Bulletin, US, 90: 197-202.

Rappé G. \& Van Waerebeek K., 1988. Xenobalanus globicipitis (Crustacea: Cirripedia) on cetaceans in the northeast Atlantic and the Mediterranean: A review. European research on cetaceans Second annual conference of the European Cetacean Society; 5-7 Feb. 1988; Troia, Portugal.

Reeves R.R. \& Notarbartolo de Sciara G., 2006. The status and distribution of cetaceans in the Black Sea and Mediterraenan Sea. Workshop Report - Monaco 57 March 2006. Malaga, Spain: IUCN The World Conservation Union, $137 \mathrm{pp}$.

Richard J., 1936. Résultats des campagnes scientifiques accomplies sur son yacht par Albert 1er Prince Souverain de Monaco. Fascicule XCIV, Vol. 94: 34-71. Gouvernement á Monaco, Monaco, 72 + VIII Plates pp.

Richard J. \& Neuville H., 1897. Sur quelques Cétacés observés pendant les Campagnes du yacht Princesse Alice. Mémoires de la Société Zoologique de France, 10: $100-109$.

Richard J. \& Neuville H., 1936. Documents sur les cétacés et pinnipeds des croisieres du Prince Albert 1er de Monaco réunis par Jules Richard. In: Richard J., Editor. Résultats des campagnes scientifiques accomplies sur son yacht par Albert 1er Prince Souverain de Monaco Fascicule XCIV. Gouvernement á Monaco, Monaco, 34-71. 
Riesch R., 2016. Species in the making. Killer whales appear to be splitting into several separate species, perhaps because cultural diferences among populations are driving them apart. Scientific American, 315: 54-61.

Sakai M., Hishii T., Takeda S. \& Kohshima S., 2006. Laterality of flipper rubbing behavior in wild bottlenose dolphins (Tursiops aduncus): Caused by asymmetry of eye use? Behavioural Brain Research, 170: 204 210. https://doi.org/10.1016/j.bbr.2006.02.018

Sakai Y., Hayashi R., Kouichi M., Yamada T. \& Asakawa M., 2009. Records of barnacle, Xenobalanus globicipitis Steenstrup, 1851 and whale lice, Cyamus sp. from a wild killer whale captured in the Western North Pacific, off Kii Peninsula, Japan. Japanese Journal of Zoo and Wildlife Medicine, 14: 81-84.

Samaras W.F., 1989. New host record for the barnacle Cryptolepas rhachianecti Dall, 1872 (Balanomorpha: Coronulidae). Marine Mammal Science, 5: 84-87. https://doi.org/10.1111/j.1748-7692.1989.tb00216.x

Scheffer V.B., 1969. Marks on the skin of a killer whale. Journal of Mammalogy, 50: 151.

Siciliano S., Cardoso J., Francisco A., De Souza S.P., Hauser-Davis R.A. \& Iwasa-Arai T., 2020. Epizoic barnacle (Xenobalanus globicipitis) infestations in several cetacean species in south-eastern Brazil, Marine Biology Research, 16: 1-13. https://doi.org/10. 1080/17451000.2020.1783450

Steenstrup J.J.S., 1852. On Xenobalanus globicipitis, en ny Cirriped-Slaegt af Coronula familien. Videnskabelige meddelelser fra den Naturhistoriske forening i Kjöbenhavn, 62-64.

Sugarman P., 1984. Field guide to the orca whales of Greater Puget Sound and Southern British Columbia. The Whale Museum, Friday Harbor, Washington. 27 pp.

Toth-Brown J. \& Hohn A.A. 2007. Occurence of the barnacle, Xenobalanus globicipitis, on coastal bottlenose dolphins (Tursiops truncatus) in New Jersey. Crustaceana, 80: 1271-1279. https://www.jstor.org/stable/ 20107916

Towers J.R., Hallé M.J., Symmonds H.K., Sutton G.J., Morton A.B., Spong P., Borrowman J.P. \& Ford J.K.B., 2018. Infanticide in a mammal-eating killer whale population. Scientific Reports, 8 : 1-8. https:// doi.org/10.1038/s41598-018-22714-X

Van Waerebeek K., Reyes J.C. \& Alfaro J., 1993. Helminth parasites and phoronts of dusky dolphins Lagenorhynchus obscurus (Gray, 1828) from Peru. Aquatic Mammals, 19: 159-169.
Vargas-Bravo M.H., Elorriaga-Verplancken F.R., OlivosOrtiz A., Morales-Guerrero B., Liñán-Cabello M.A. \& Ortega-Ortiz C.D., 2020. Ecological aspects of killer whales from the Mexican Central Pacific coast: Revealing a new ecotype in the Eastern Tropical Pacific. Marine Mammal Science, 1-16. https://doi.org/ $10.1111 / \mathrm{mms} .12748$

Visser I.N., 1998. Prolific body scars and collapsing dorsal fins on killer whales (Orcinus orca) in New Zealand waters. Aquatic Mammals, 24: 71-81.

Visser I.N., 2000. Orca (Orcinus orca) in New Zealand waters PhD Thesis. Auckland: University of Auckland, $194 \mathrm{pp}$.

Visser I.N., 2012. Report on the physical \& behavioural status of Morgan, the wild-born Orca held in captivity, at Loro Parque, Tenerife, Spain. Free Morgan Foundation. 35 pp.

Visser I.N. \& Cooper T.E., 2020a. It's not black and white: Orca ecotypes in New Zealand. 5th World Conference on Marine Biodiversity; 13-16 December 2020; Auckland, New Zealand.

Visser I.N. \& Cooper T.E., 2020b. Orca Research Trust guide to New Zealand orca. Black and White Fish Publications, Tutukaka, New Zealand, 40 pp.

Visser I.N. \& Mäkeläinen P., 2000. Variation in eye-patch shape of killer whales (Orcinus orca) in New Zealand waters. Marine Mammal Science, 16: 459-469. https://doi.org/10.1111/j.1748-7692.2000.tb00938.x

Visser I.N., Zaeschmar J., Haliday J., Abraham A., Ball P., Bradley R., Daly S., Hatwell T., Johnson T., Johnson W., Kay L., Maessen T., McKay V., Turner N., Umuroa B. \& Pace D.S., 2010. First record of predation on false killer whales (Pseudorca crassidens) by killer whales (Orcinus orca). Aquatic Mammals. 36: 195-204. https://doi.org/10.1578/AM.36.2.2010.195

Wethey D.S., Luckenbach M.W. \& Kelly C.A., 1988. Larval settlement in barnacles; influence of water flow. In: Thompson M.F., Sarojoini R. \& Nagabhushanam R., Editors. Marine Biodeterioration. Oxford \& IBH Publishing Co. Pvt. Ltd, New Delhi, 499-511.

Whitehead T.O., Rollinson D.P. \& Reisinger R.R., 2014. Pseudostalked barnacles Xenobalanus globicipitis attached to killer whales Orcinus orca in South African waters. Marine Biodiversity Records, 45: 873-876. https://doi.org/10.1007/s12526-014-0296-2

Xinwei Z., Tao J. \& Song Q., 2015. Deriving inherent optical properties from background color and underwater image enhancement. Ocean Engineering, 94: 163-172. http://dx.doi.org/10.1016/j.oceaneng.2014. 11.036 


\section{Supplemental Material S-1. Xenobalanus in manuscripts from Richard \& Neuville (1896), Gruvel (1920), Richard (1936) and Richard \& Neuville (1936), with discrepancies in citations of these records.}

During our review of records of orca hosting Xenobalanus globicipitis (hereafter referred to as Xenobalanus), we noticed some discrepancies/anomalies regarding three records and how they are cited. The unravelling of the issues should help to prevent further replication of the misinterpretation of the original data.

We use YYYYMMDD format to avoid complications between North American and other date formats.

\section{1. 'Monaco'}

On 18960527, off the coast of Monaco two orca were harpooned and killed. This was first reported by Richard \& Neuville (1897) in the scientific journal Mémoires de la Société Zoologique de France, volume X, pages 100-109.

Richard \& Neuville (1897) on pages 105-108, give the date and the location as Station 638. The text also states the capture was "off the coast from Monaco". The authors give the longitude as $4^{\circ} 57^{\prime} 45^{\prime \prime} \mathrm{E}$ (which appears to be the departure point (Fos-ser-Mer / Port-deBoc) rather than the capture point $\left[7^{\circ} 18^{\prime} \mathrm{E}\right]$, see Richard \& Neuville (1936) for capture location \& Table S-1.1 for comparisons \& Fig. S-1.1 for map).

Richard \& Neuville (1897) mention that the orca was harpooned and give the total length measurement of the two females. They also mention Xenobalanus on the pectoral fins and tail flukes of the larger of the two orca.
There is one photograph of a dead female orca lying on her right side, showing her ventral surfaces and a rope around her tail (see last row of Table S-1.1).

This 1896 record is often erroneously attributed to other authors such as Richard (1936), see below for details.

Gruvel (1920), page 55 has the heading Genre Xenobalanus, Steenstrup 1951 [sic], and "Xenobalanus globicipitis Steenstrup". On page 56 Gruvel (1920) mentioned the $\mathbf{1 8 9 6 0 5 2 7}$ event, but gives only these basic details; "Expedition of 1896: Stn. [station] 638 on an orca (Orca gladiator)" [translated'] (i.e., he refers to the Richard \& Neuville (1897) record, but no description is given of the location, other than mention of the station number).

Gruvel (1920) is sometimes listed as 'Mediterranean' in subsequent citations. Additionally, and erroneously, Gruvel (1920) is at times cited as the source publication for the 18960527 record (however, see below regarding the 19020722 record off Spain).

Richard (1936) is a volume comprised of various sections / chapters / publications, some of which have been previously published. Jules Richard is the Editor of the volume. This volume is often cited as the source for the 18960527 record. While in and of itself this isn't 100\% incorrect, as a reprint of the Richard \& Neuville (1897) manuscript is contained inside (albeit modified, see below and see Table S-1.1), it isn't 100\% precise either. Furthermore, in order to be accurate, the 
authors should be cited as Richard \& Neuville (1936), not solely Richard (1936).

Richard \& Neuville (1936) is a reprint of the Richard \& Neuville (1897) scientific publication. Immediately following the title in the 1936 version is an *, which leads to a footnote giving an abbreviation of the Journal Mémoires de la Société Zoologique de France, the volume number (10) and the year; ("Mém. Soc. Zool. De France, x, 1897”), i.e., making reference to the original manuscript being published in 1897. However, we note that in this volume the text is changed somewhat (including adding in the 'Spain' ('Gibraltar') record as described below).

Richard \& Neuville (1936) provide identical information in their pages 13-14 as the original (1897) publication, with the exception of correcting a longitude (see Table S-1.1). From that point forward there is additional data regarding the 1896052 record that was not included in the Richard \& Neuville (1897) version. Richard \& Neuville (1936) add that the animals were harpooned in the morning and details of the behaviour of the mother to her injured offspring. They also provided a detailed table of measurements of each of the two dead females (the mother and her presumed offspring). They note that some organs were preserved in salt.

\section{2. 'Spain' ('Gibraltar')}

On 19020722 off the coast of Spain an orca was harpooned and killed. This was first described by Gruvel (1920), who only gives these basic details. "Expedition of 1902. Stn. [station] 1267 on an orca (Orca gladiator)" [translated'] (i.e., there is no mention made of the location other than the station number). The 19020722 record appears to be linked to Gruvel (1902) (see Table S-1.3), however we could find no details of either an orca capture nor records of Xenobalanus on an orca in the Gruvel (1902) record and, as such, we believe that the Gruvel (1920) publication is therefore the original source of information for the 19020722 record.

Richard \& Neuville (1936) provide more data regarding the same $\mathbf{1 9 0 2 0 7 2 2}$ record. These authors mention 'near Gibraltar'. However, more accurately, from the latitude and longitude we can ascertain that the capture was approximately $30 \mathrm{~km}$ to the east of Gibraltar, and approximately $6.5 \mathrm{~km}$ off the coast of La Chullera. It was therefore off the coast of Spain (See Fig S-1.1) although it is often cited erroneously as a record from 'Gibraltar'.

Of note is that although the Richard \& Neuville (1936) has an asterisk by the title, with a footnote that indicates the manuscript is a reprint of their 1897 manuscript (see section 1, above), it is not an exact replica. Rather it is modified to include this Spanish record (along with records of other cetacean species captured) (see Table S-1.1 for orca specific details). Additionally, the longitude in the text has been changed from the 1897 publication, to reflect the capture point, rather than the presumed departure point.

\section{HOW HAVE THESE RECORDS BEEN CITED?}

We note that authors, when discussing Xenobalanus on orca, typically do not cite Richard \& Neuville (1897). In fact, we could find no recent publications that mention the 1897 publication at all, despite discussing the record from 18960527.

Instead, some cite Gruvel (1920) solely, or they may treat Gruvel (1920) and Richard \& Neuville (1936) as if they were each an original record and overlook that both publications are referring to the same two records (e.g., Rajaguru \& Shantha (1992), in their Table 1, list 'Mediterranean' for Gruvel (1920) and 'Gibraltar' for Richard (1936) - i.e., they also have the location incorrect). 
Or, authors may conflate the two (e.g., Whitehead et al. (2014) "in the Mediterranean (Gruvel 1920; Richard 1936)"), or authors may cite Gruvel (1920) without any reference to location, just host species (e.g., NilssonCantell, 1930 "Orcinus orca (acc. To Gruvel, 1920)").

Although we too list Gruvel (1920), that is done because it was the first published record of the capture of the La Chullera Spanish (aka erroneously referred to as the 'Gibraltar') orca, from which Richard \& Neuville (1936) later describes the Xenobalanus.

And, although some authors conflate the two La Chullera and Monaco records into the 'Mediterranean Sea', we keep them separate (and therefore indicate each as separate 'regions' in Fig. 1 in our manuscript), because of the geographical distance of $\sim 1,500 \mathrm{~km}$ between Monaco and La Chullera (i.e., a similar distance between the Galápagos Island and Costa Rica $(\sim 1,200 \mathrm{~km})$ and more than the distance between the Canary Islands and Gibraltar $(\sim 1,000 \mathrm{~km})$ and such a distance suggests both oceanographic and regionally biological differences are likely occurring between Monaco and Spain.

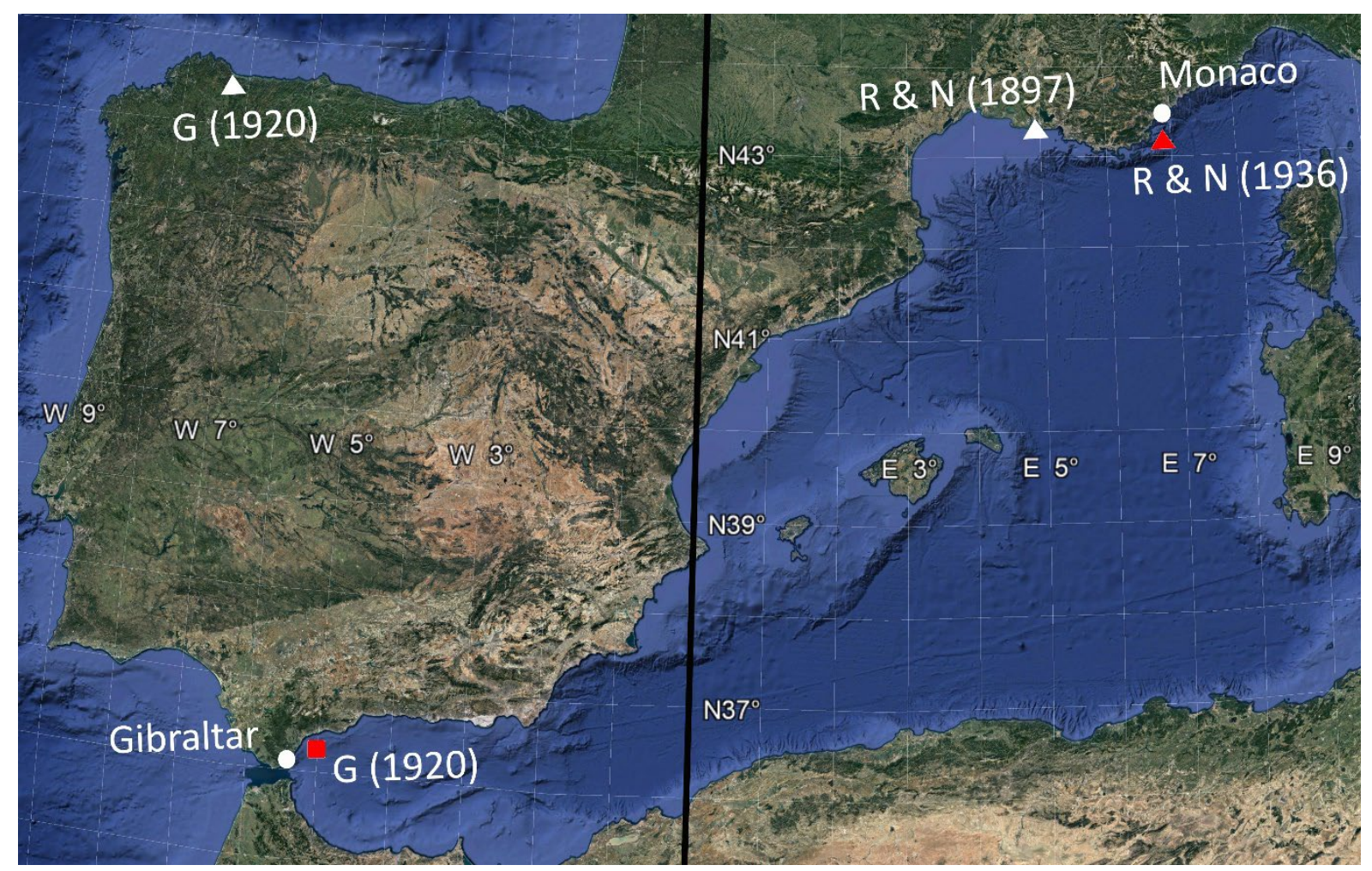

Figure S-1.1. Places referred to in the Richard \& Neuville (1897) (R \& N (1897); Gruvel (1920), (G (1920)); and Richard \& Neuville (1936), (R \& N (1936). The $\mathbf{1 8 9 6 0 5 2 7}$ record was captured off Monaco (red triangle), whilst the $\mathbf{1 9 0 2 0 7 2 2}$ was captured approximately $6.5 \mathrm{~km}$ off the coast of $\mathbf{L a}$ Chullera, Spain (red square). Of note is that the latter is often referred to as captured off Gibraltar, however it was $30 \mathrm{~km}$ from Gibraltar and therefore well inside Spanish waters. 


\section{REFERENCES.}

Gruvel J.A. 1902. Chapter 1, Expéditions scientifiques du "Travailleur" et du "Talisman" : Cirrhipèdes. In: A M-E \& Perrier E, Editors. Expéditions scientifiques du "Travailleur" et du "Talisman" Pendant les années 1880, 1881, 1882, 1883. Msson et Cie, Éditeurs, Libraires de L'Académie de Médecine, Paris, 1-178 + VII Plates.

Gruvel J.A. 1920. Cirrhipedes provenant des campagnes scientifiques de S.A.S.le Prince de Monaco (18851913). In; Résultas des Campagnes Scientifiques accomplies sur son yacht par Albert ler, Prince Souverain de Monaco. [Cirripeds from the scientific campaigns of $\mathrm{HSH}$ the Prince of Monaco (1885-1913). In; Results of scientific campaigns compiled on his Yacht by Albert 1st Prince Sovereign of Monaco. Published under his direction with the assistance of M. Jules Richard, Doctor of Sciences, in charge of Zoological works on board. Volume 53]. Monaco. 1-88 pp.

Richard J. \& Neuville H. 1897. Sur quelques Cétacés observés pendant les Campagnes du yacht Princesse Alice. Mémoires de la Société Zoologique de France. X:100-109.

Richard J. \& Neuville H. 1936. Documents sur les cétacés et pinnipeds des croisieres du Prince Albert 1er de Monaco réunis par Jules Richard [Documents on cetaceans and pinnipeds from the campaigns of Prince Albert 1st of Monaco collected by Jules Richard. In; Results of scientific campaigns carried out on his yacht by Albert 1st Prince Sovereign of Monaco. Volume 94]. In: Richard J, Editor. Résultats des campagnes scientifiques accomplies sur son yacht par Albert 1er Prince Souverain de Monaco Fascicule XCIV. Gouvernement á Monaco, Monaco, 34-71. 
Table S-1.1. Comparing Richard \& Neuville (1897) verses Richard \& Neuville (1936) shows that the (1897) record should take precedence for the 1896 orca capture and therefore also the Xenobalanus globicipitis record. The two publications differ in that the 1897 publication was originally published in a scientific journal whilst the 1936 publication was a reprint as a chapter in a volume (report/book) $\boldsymbol{A N D}$ there is reference to another orca capture on 19020722 (La Chullera Spain, often erroneously cited as Gibraltar). We present comparisons between the two publications to clarify that for the 18960527 orca record (Monaco), the 1897 version should be cited as the original source. For the 19020722 orca record (i.e., La Chullera, Spain), Gruvel (1920) should be cited as the original record of the capture of the orca ${ }^{1}$. Comments in ["square brackets and italics"] are translations. Comments in [square brackets \& no italics] are additional information, such as clarification of a point. Underlined is different or new.

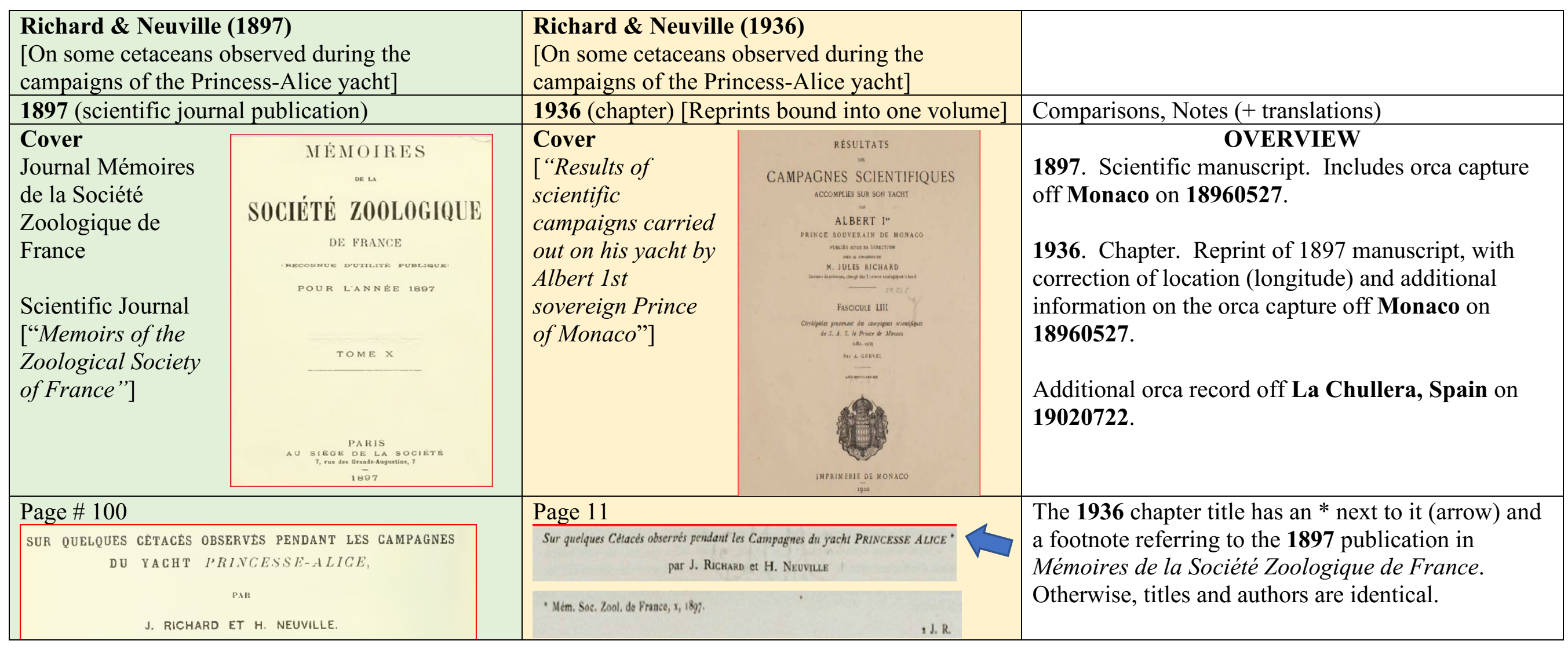

\footnotetext{
${ }^{1}$ See Table S-1.2 for details regarding Gruvel (1920)
} 


\begin{tabular}{|c|c|c|}
\hline 1897 (scientific journal publication) & $\begin{array}{l}1936 \text { (chapter) [Reprints bound into one } \\
\text { volume] }\end{array}$ & Comparisons, Notes (+ translations) \\
\hline 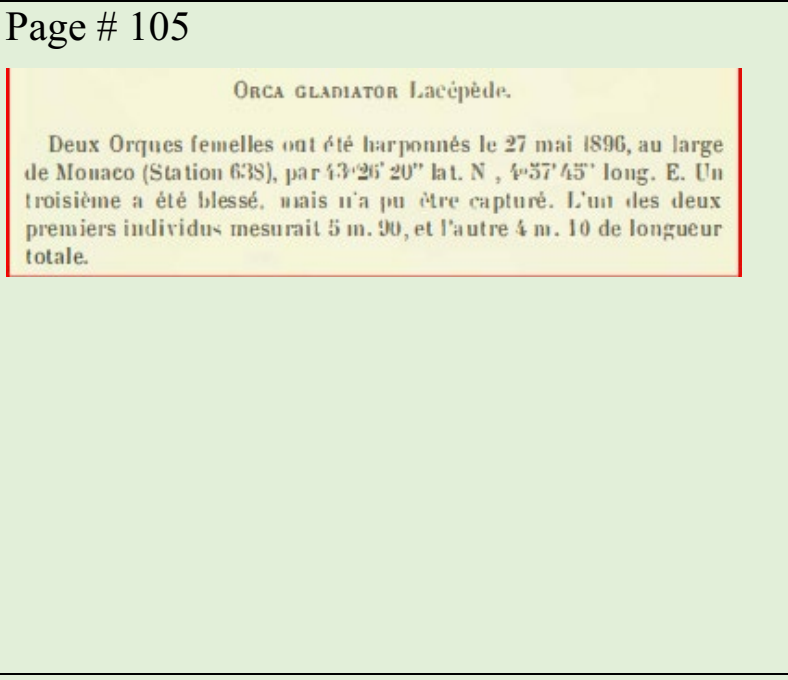 & 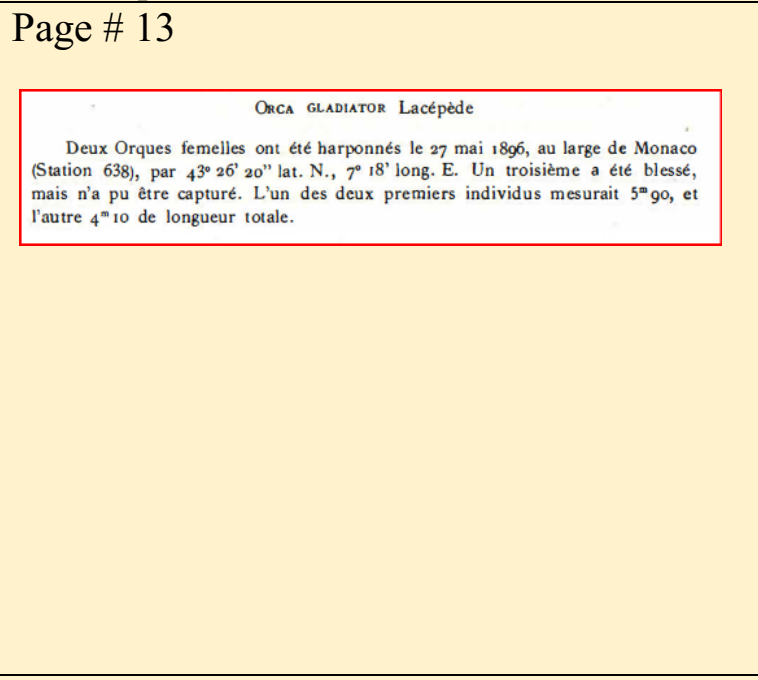 & $\begin{array}{l}\text { 1897 publication gives the longitude as } 4^{\circ} 57^{\prime} 45^{\prime} \text { E for } \\
\text { the location (which appears to be the departure point; } \\
\text { Fos-ser-Mer / Port-de-Bouc). } \\
1936 \text { reprint gives } 7^{\circ} 18^{\prime} \text { E (which appears to be the } \\
\text { correct capture location; off the coast of Monaco). } \\
\text { Otherwise, the text is identical } \\
\text { ["Two female killer whales were harpooned on May } \\
27,1896, \text { off the coast from Monaco (Station 638), at } \\
43^{\circ} 26^{\prime} 20^{\prime \prime} \text { lat. } N \text {, } 4^{\circ} 57^{\prime} 45^{\prime \prime} \text { long. E. } \\
\text { A third one was wounded, but could not be captured. } \\
\text { Of the first two individuals, one measured } 5 \mathrm{~m} \mathbf{9 0} \text {, and } \\
\text { the other } 4 \mathrm{~m} 10 \text { in total length"]. }\end{array}$ \\
\hline $\begin{array}{l}\text { Page \# 106/107 } \\
\text { Comme parasites, nons avons à signaler plusieurs . Yenobalanus } \\
\text { qui étaient fixés sur la queue et sur la pectorale du grand Orque. }\end{array}$ & $\begin{array}{l}\text { Page \# } 14 \\
\begin{array}{l}\text { Comme parasites, nous avons à signaler plusieurs Xemobalamus qui tetaient } \\
\text { fixts sur la queue ef sur la pectorale du grand Orque. }\end{array}\end{array}$ & $\begin{array}{l}\text { Text is identical } \\
1897 \\
1936 \\
\text { ["As parasites, we have to report several } \\
\text { Xenobalanus which were attached to the tail and } \\
\text { pectoral of the large Orca"] }\end{array}$ \\
\hline 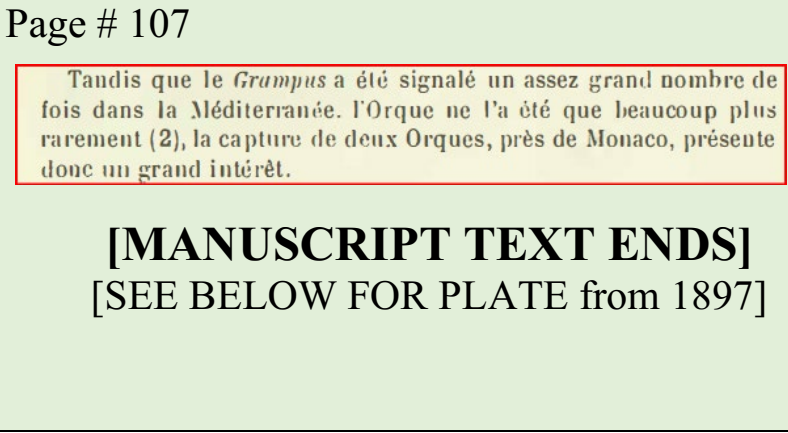 & 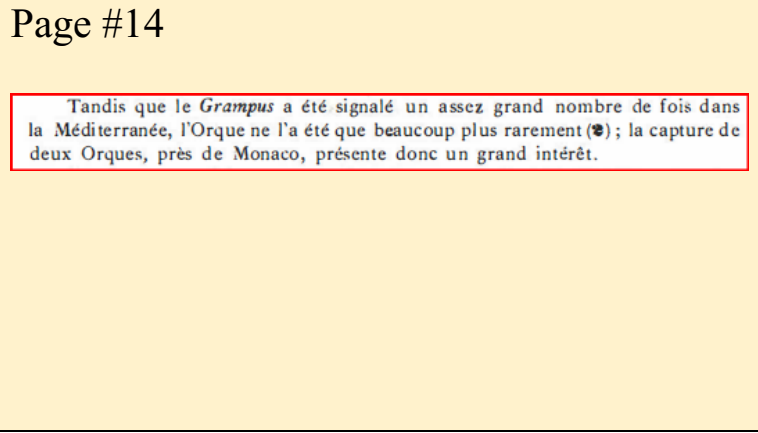 & $\begin{array}{l}\text { Text is identical } \\
\mathbf{1 8 9 7} \\
\mathbf{1 9 3 6} \\
\text { ["While the Grampus has been reported quite a } \\
\text { number of times in the Mediterranean. The Orca has } \\
\text { been so much more rarely (2), so the capture of two } \\
\text { Orcas, near Monaco, is of great interest."] [note: the } \\
\text { (2) is not clear with regards to its meaning, it may be } \\
\text { that they have sighted them only twice]. }\end{array}$ \\
\hline
\end{tabular}




\begin{tabular}{|c|c|c|}
\hline 1897 (scientific journal publication) & 1936 (chapter) [Reprints bound into one volume] & Comparisons, Notes (+ translations) \\
\hline $\begin{array}{l}\qquad \text { No further text } \\
\text { [SEE BELOW FOR PLATE from 1897] }\end{array}$ & 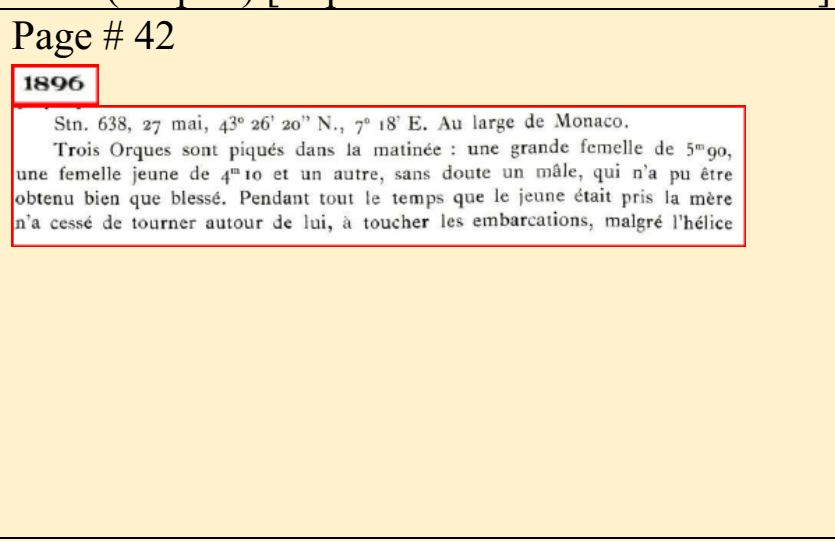 & $\begin{array}{l}\text { 1936 reprint } \\
\text { [“Station } 638,27 \text { May } 1896.43^{\circ} 26^{\prime} 20^{\prime \prime} N ., 7^{\circ} 18^{\prime} E \text {. } \\
\text { Off the coast of Monaco"] } \\
\text { Also gives this additional text (underlined): } \\
\text { [“Three killer whales are hit in the morning, a } \\
\text { longer female of } 5 \mathrm{~m} 90, \text { a young female of } 4 m 10 \text { and } \\
\text { another, without doubt a male, which could not be } \\
\text { obtained although injured. During all the time that } \\
\text { the young was caught, the mother kept circling } \\
\text { around it, touching the boats, despite the propeller.'] }\end{array}$ \\
\hline $\begin{array}{l}\qquad \text { No further text } \\
\text { [SEE BELOW FOR PLATE from 1897] }\end{array}$ & 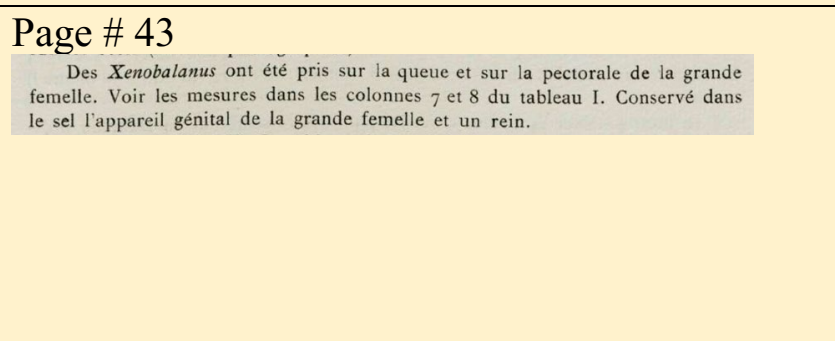 & $\begin{array}{l}\mathbf{1 9 3 6} \text { reprint } \\
\text { Also gives this additional text (underlined): } \\
\text { ["Xenobalanus were taken from the tail and } \\
\text { pectoral of the large female. See the measurements } \\
\text { in columns } 7 \text { and } 8 \text { of Table I [orca measurements]. } \\
\text { The genital tract of the large female and a kidney } \\
\text { are preserved in salt."] }\end{array}$ \\
\hline $\begin{array}{l}\text { No further text } \\
\text { [SEE BELOW FOR PLATE from 1897] }\end{array}$ & 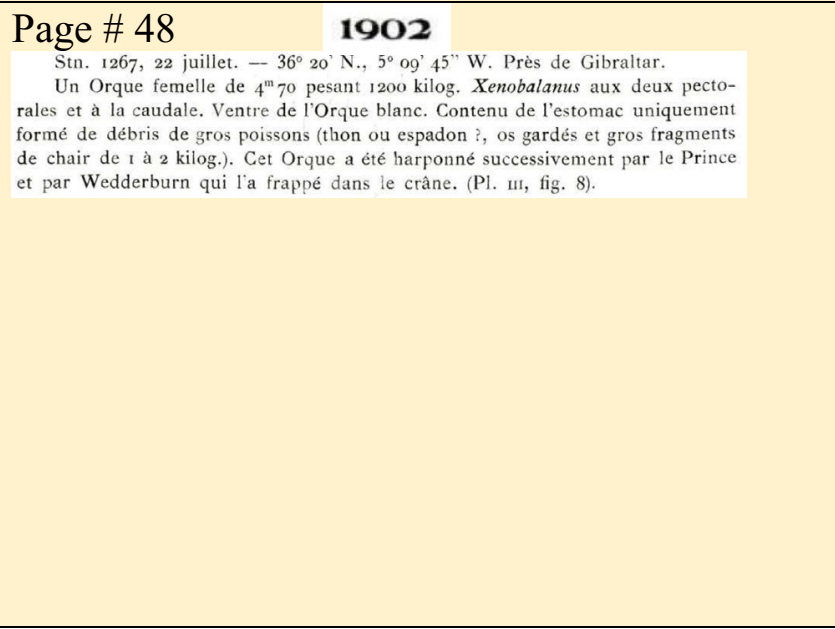 & $\begin{array}{l}\mathbf{1 9 3 6} \\
\text { An additional record is noted from } 1902 \text { (see Gruvel } \\
\mathbf{1 9 0 2} \&(\mathbf{1 9 2 0}), \text { below) } \\
\text { "Stn. } 1267,22 \text { july [1902]. }-36^{\circ} 20^{\prime} N ., 5^{\circ} 09^{\prime} 45^{\prime} \\
\text { W. Near Gibraltar. One female orca of } 4 \mathbf{m} 70 \\
\text { weighing } 1,200 \mathrm{~kg} \text {. Xenobalanus on both pectorals } \\
\text { and on the caudal [posterior]. The belly of the orca } \\
\text { is white. Contents of the stomach were only } \\
\text { composed of big fish debris. (tuna and swordfish? } \\
\text { untouched bones and big fragments of meat from } 1 \\
\text { to } 2 \text { kilos) This orca was harpooned successively by } \\
\text { the Prince and by Wedderburn who hit it in the skull. } \\
\text { (Pl, III, fig 8).". }\end{array}$ \\
\hline
\end{tabular}




\begin{tabular}{|c|c|c|}
\hline 1897 (scientific journal publication) & 1936 (chapter) [Reprints bound into one volume] & Comparisons, Notes $(+$ translations $)$ \\
\hline $\begin{array}{l}\text { No further text } \\
\text { [SEE BELOW FOR PLATE from 1897] }\end{array}$ & 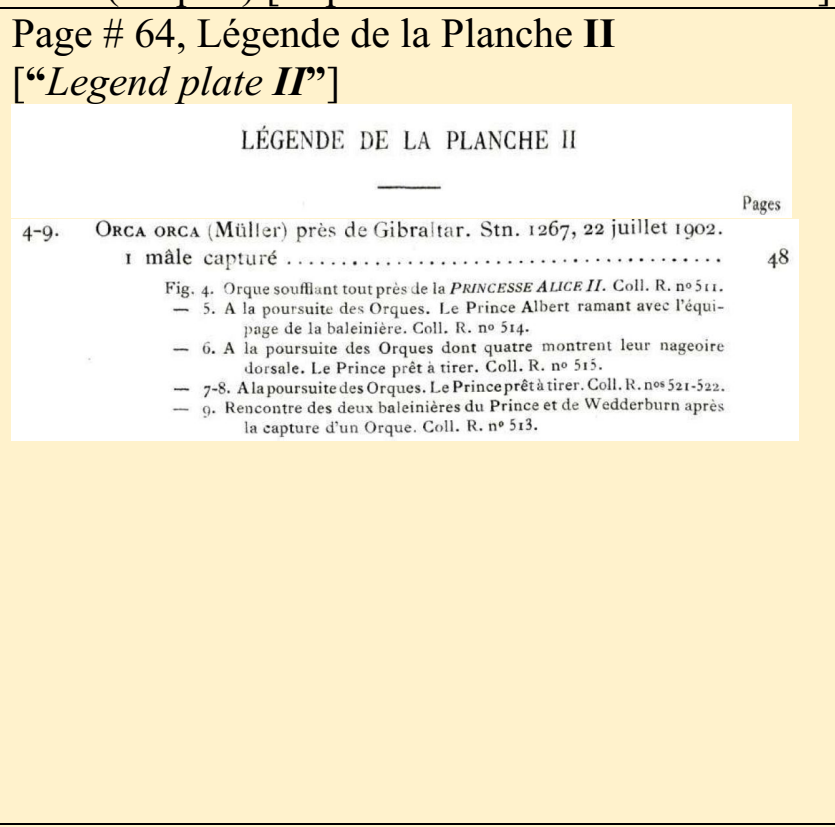 & $\begin{array}{l}\text { [See Gruvel (1920) below for original details] } \\
\text { [“ORCA ORCA (Müller) near Gibraltar. Stn. [station] } \\
1267 \text { 22nd July 1902, } 1 \text { male captured ...[page]. } 48 \\
\text { Fig. 4. Orca blowing near the Princess Alice II. } \\
\text { Coll. R. } n^{\circ} 511 \\
\text {-5. Going after the orca. The Prince Albert is rowing } \\
\text { with the crew of the whaler. Coll. R. no } 514 \\
\text {-6. Going after the orca from which } 4 \text { are showing } \\
\text { their dorsal fin. The Prince is ready to shoot. } \\
\text { Coll.R.no } 515 \\
-7-8 \text { Going after the [male] orca. The Prince is } \\
\text { ready to shoot. Coll. R. } n^{\text {os }} 521-522 \text {. } \\
-9 . \text { Meeting of two whalers of the Prince and of } \\
\text { Wedderburn after the capture of one orca.Coll.R.no } \\
\text { 513"] } \\
\text { [Note: Fig. } 5 \text { (not reproduced here) only pictured the } \\
\text { men rowing, no orca visible.] }\end{array}$ \\
\hline $\begin{array}{l}\text { No further text } \\
\text { [SEE BELOW FOR PLATE from 1897] }\end{array}$ & 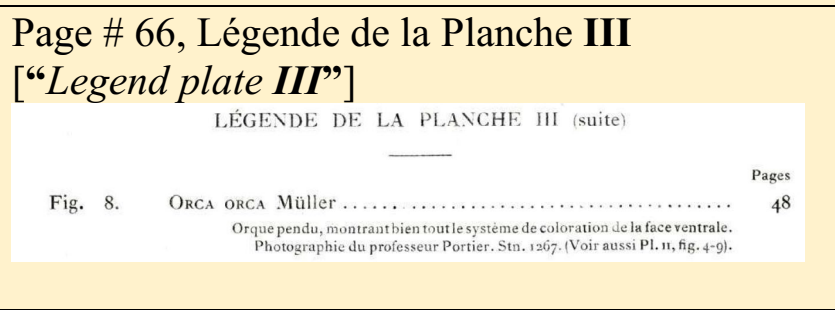 & $\begin{array}{l}\mathbf{1 9 3 6} \\
{[\mathbf{1 9 0 2 0 7 2 2}]} \\
\text { [“Fig. 8. ORCA ORCA Müller ....... [page] } 48 \\
\text { Orca hanging, showing the coloration system on the } \\
\text { ventral side. Photograph taken by Professor Portier. } \\
\text { Stn. } 1267 \text { (See also PL. II, fig. 4-9)"] }\end{array}$ \\
\hline $\begin{array}{l}\text { No further text } \\
\text { [SEE BELOW FOR PLATE from 1897] }\end{array}$ & 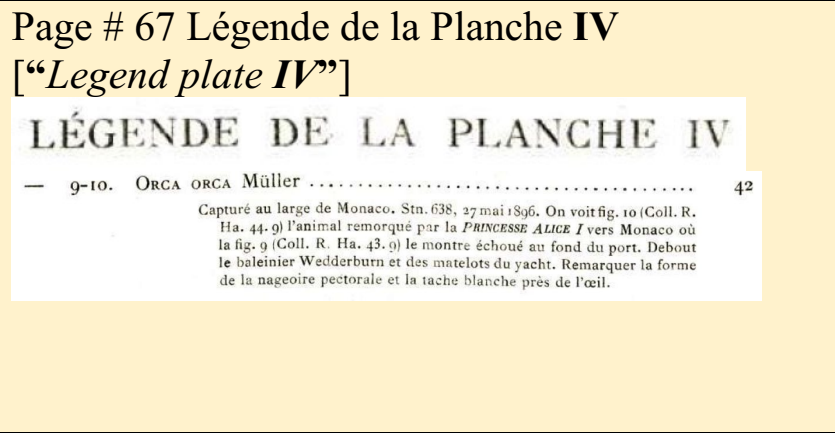 & $\begin{array}{l}\mathbf{1 9 3 6} \\
\text { ["-9-10. ORCA ORCA Müller ....... [page] } 42 \\
\text { Captured off Monaco. Stn 638, } 27 \text { May 1896. We } \\
\text { see fig. } 10 \text { (Coll. R. Ha. 44.9) the animal was towed } \\
\text { by the Princess Alice I towards Monaco where fig. } 9 \\
\text { (Coll. R. Ha. 43.9) shows it beached in the port. } \\
\text { Standing up [by the orca is] the whaler Wedderburn } \\
\text { and some sailors of the yacht. Notice the shape of } \\
\text { the pectoral fin and the white mark near the eye."] }\end{array}$ \\
\hline
\end{tabular}




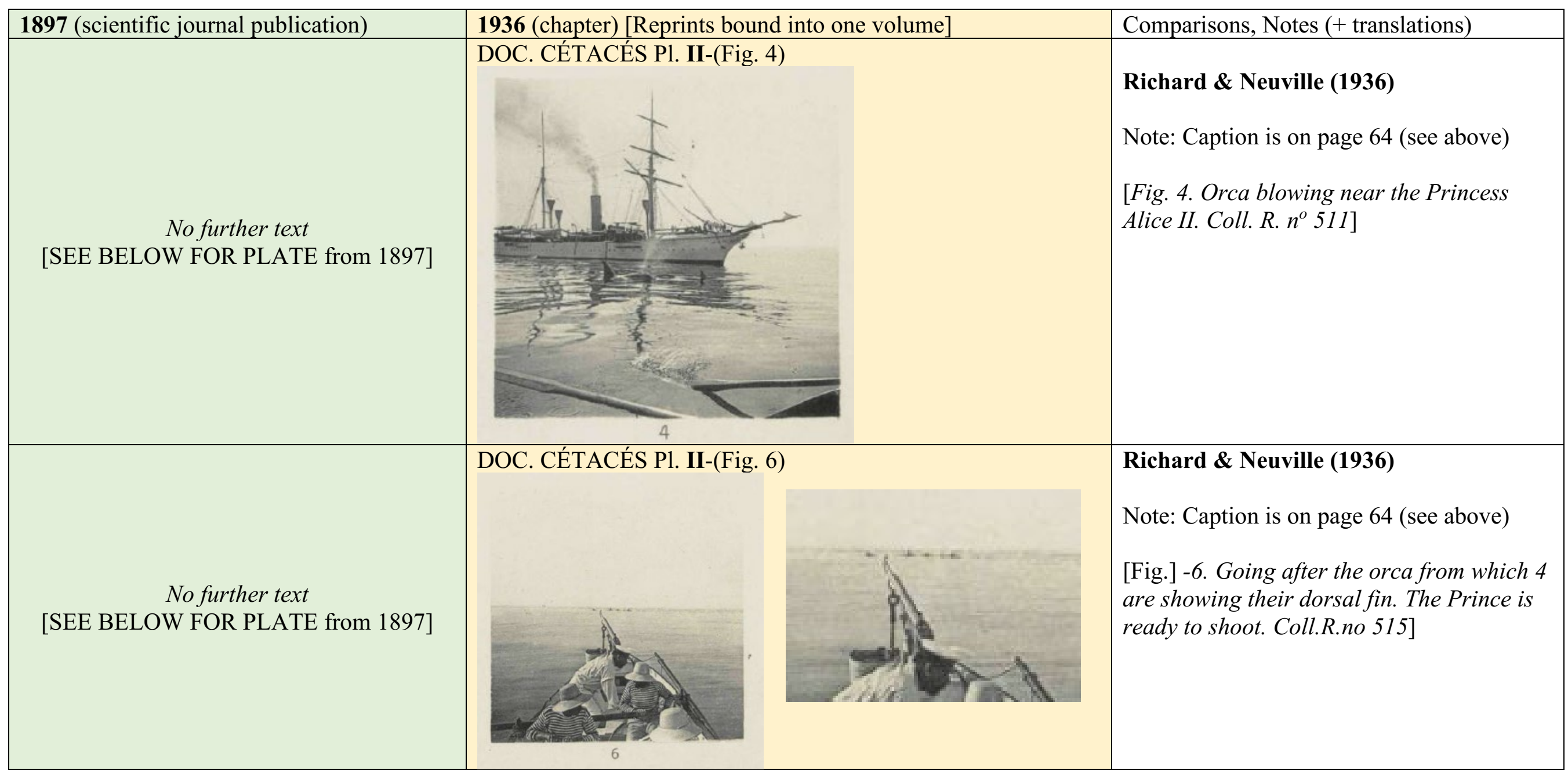




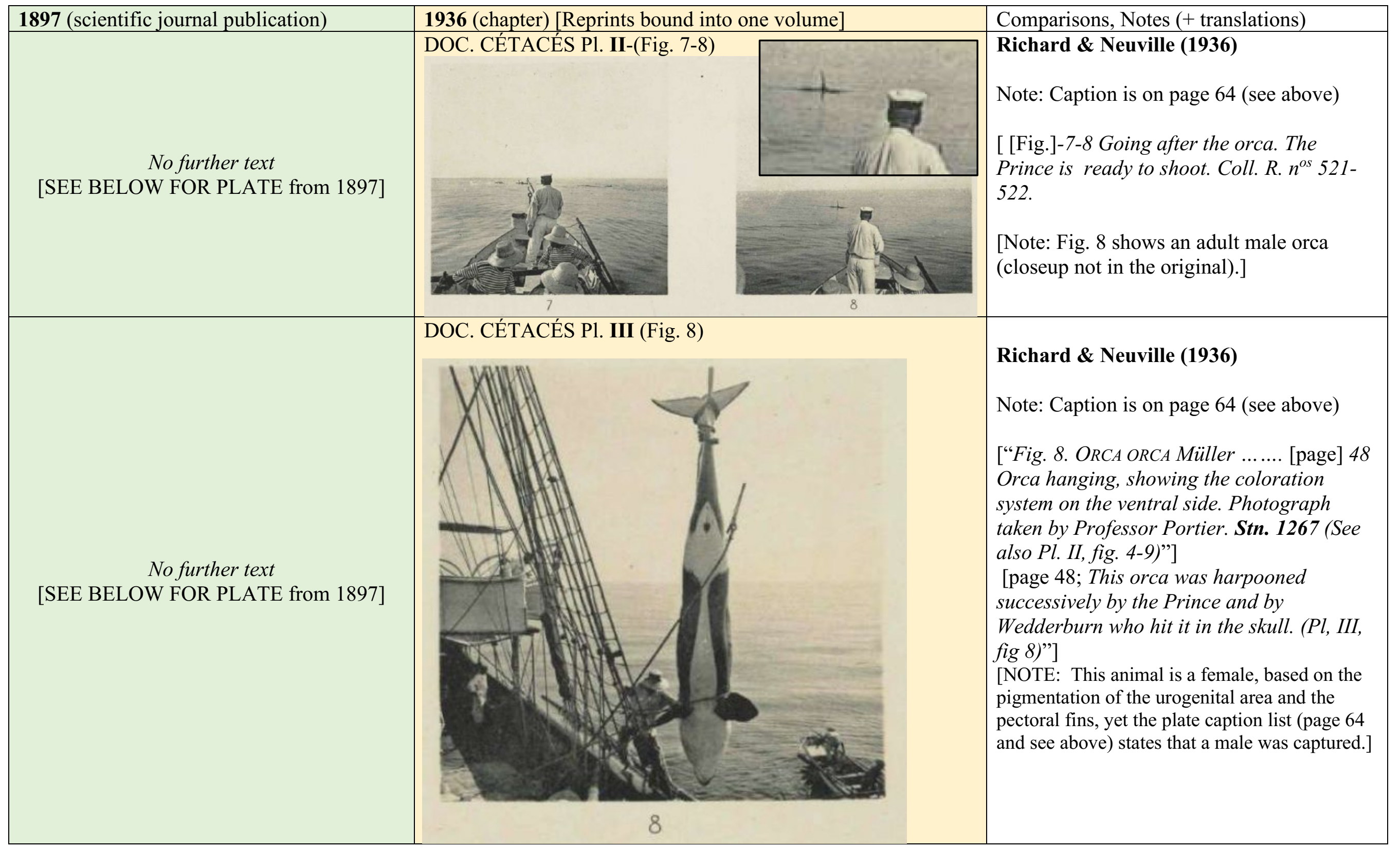




\begin{tabular}{|c|c|c|}
\hline 1897 (scientific journal publication) & 1936 (chapter) [Reprints bound into one volume] & Comparisons, Notes (+ translations) \\
\hline $\begin{array}{l}\text { No further text } \\
\text { [SEE BELOW FOR PLATE from 1897] }\end{array}$ & 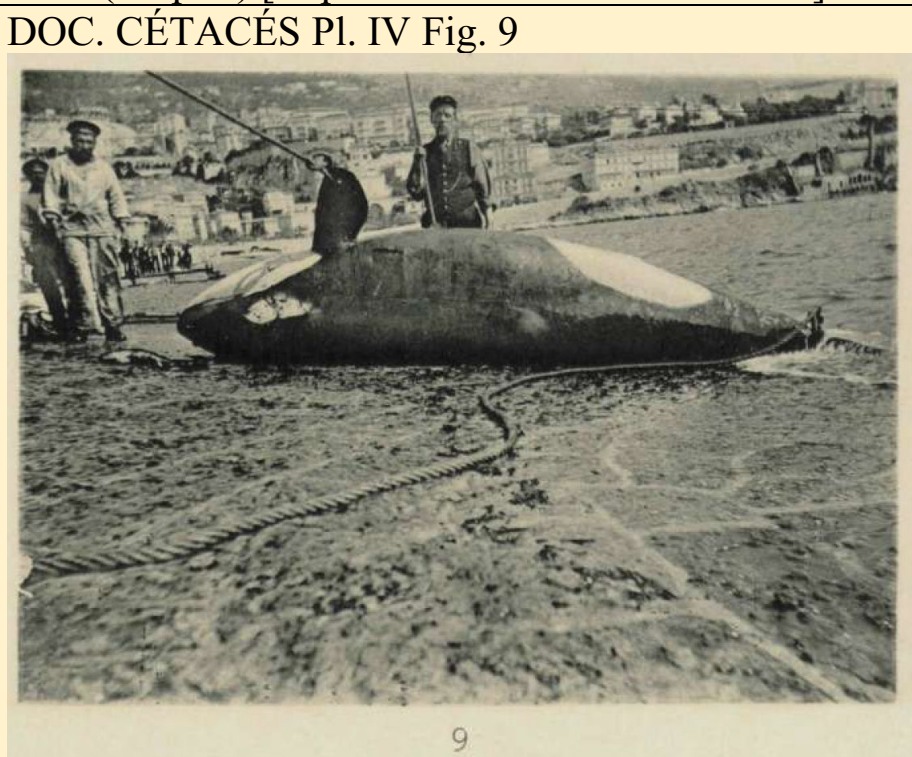 & $\begin{array}{l}\text { Richard \& Neuville (1936) } \\
\text { Note: Caption is on page } 67 \text { (see above) } \\
\text { [“-9-10. ORCA ORCA Müller ....... [page] } \\
42 \\
\text { Captured off Monaco. Stn 638, 27 May } \\
\text { 1896. We see fig. } 10 \text { (Coll. R. Ha. } 44.9 \text { ) the } \\
\text { animal was towed by the Princess Alice I } \\
\text { towards Monaco where fig. } 9 \text { (Coll. R. Ha. } \\
\text { 43.9) shows it beached in the port. } \\
\text { Standing up [by the orca is] the whaler } \\
\text { Wedderburn and some sailors of the yacht. } \\
\text { Notice the shape of the pectoral fin and the } \\
\text { white mark near the eye."] }\end{array}$ \\
\hline $\begin{array}{l}\text { No further text } \\
\text { [SEE BELOW FOR PLATE from 1897] }\end{array}$ & DOC. CÉTACÉS Pl. IV Fig 10 & $\begin{array}{l}\text { 1936 } \\
\text { [“Fig. 8. ORCA ORCA Müller ....... [page] } \\
42 \\
\text { [“-9-10. ORCA ORCA Müller ....... [page] } \\
42 \\
\text { Captured off Monaco. Stn 638, 27 May } \\
\text { 1896. We see fig. 10 (Coll. R. Ha. 44.9) the } \\
\text { animal was towed by the Princess Alice I } \\
\text { towards Monaco...] }\end{array}$ \\
\hline
\end{tabular}




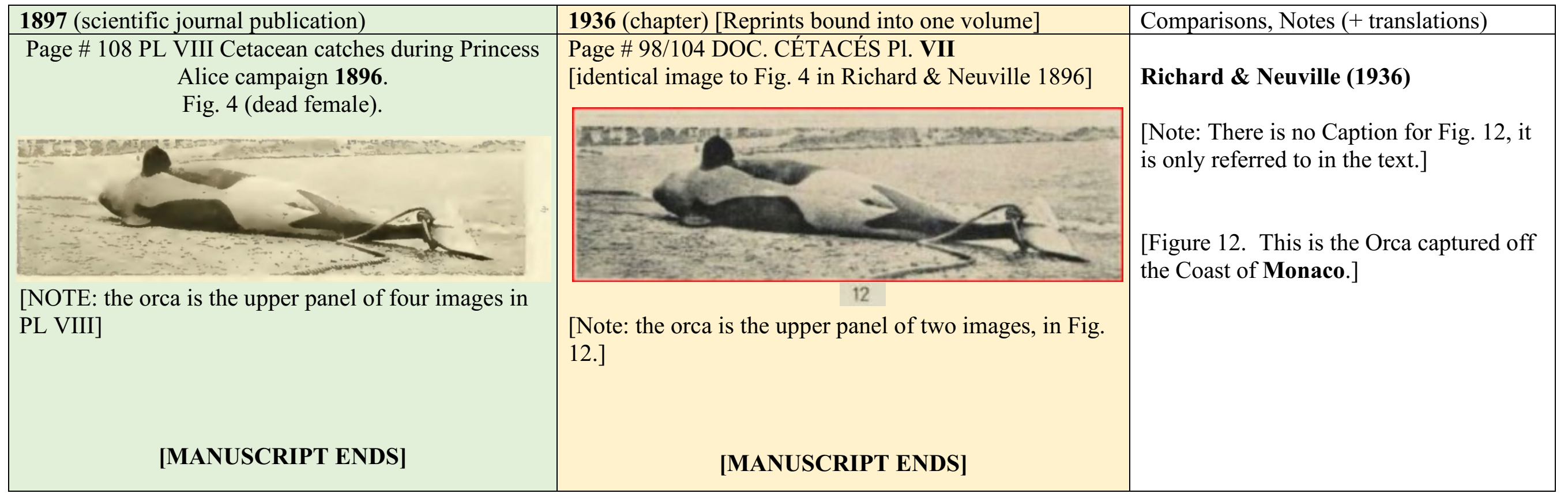


Table S-1.2. Records of Xenobalanus globicipitis. In 1902 a female orca was captured (see Table S-1.1). We present here how that record has been represented in the early literature, with details from Gruvel (1902) \& (1920) verses Richard (1936).

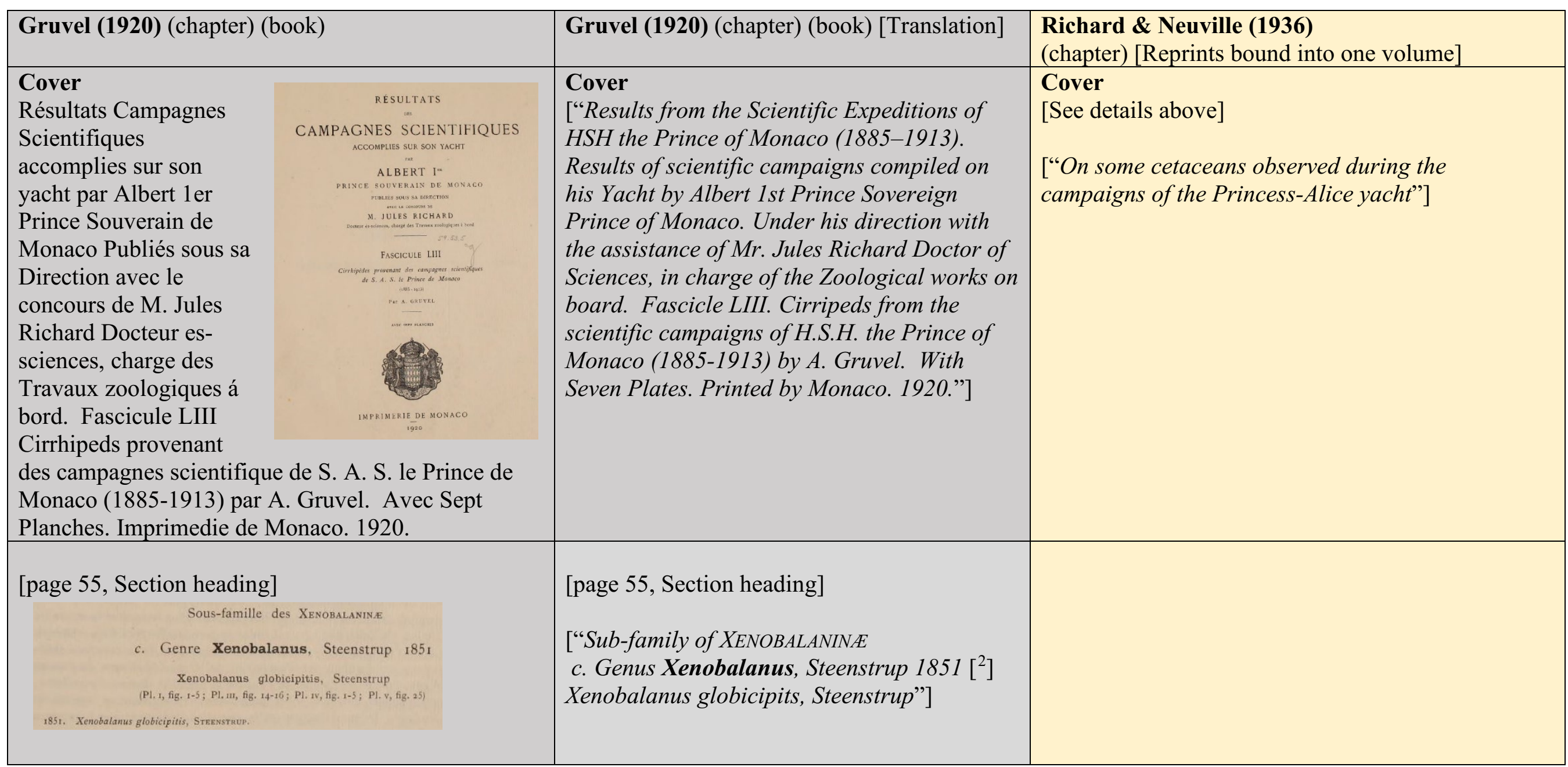

\footnotetext{
${ }^{2}$ Steenstrup described Xenobalanus in 1851, however he didn’t publish his description until 1852. Steenstrup J.J.S. 1852. On Xenobalanus globicipitis, en ny Cirriped-Slaegt af Coronula familien. Videnskabelige meddelelser fra den Naturhistoriske forening i Kjöbenhavn.62-64. (http://www. marinespecies.org/aphia.php?p=taxdetails\&id=106237)
} 


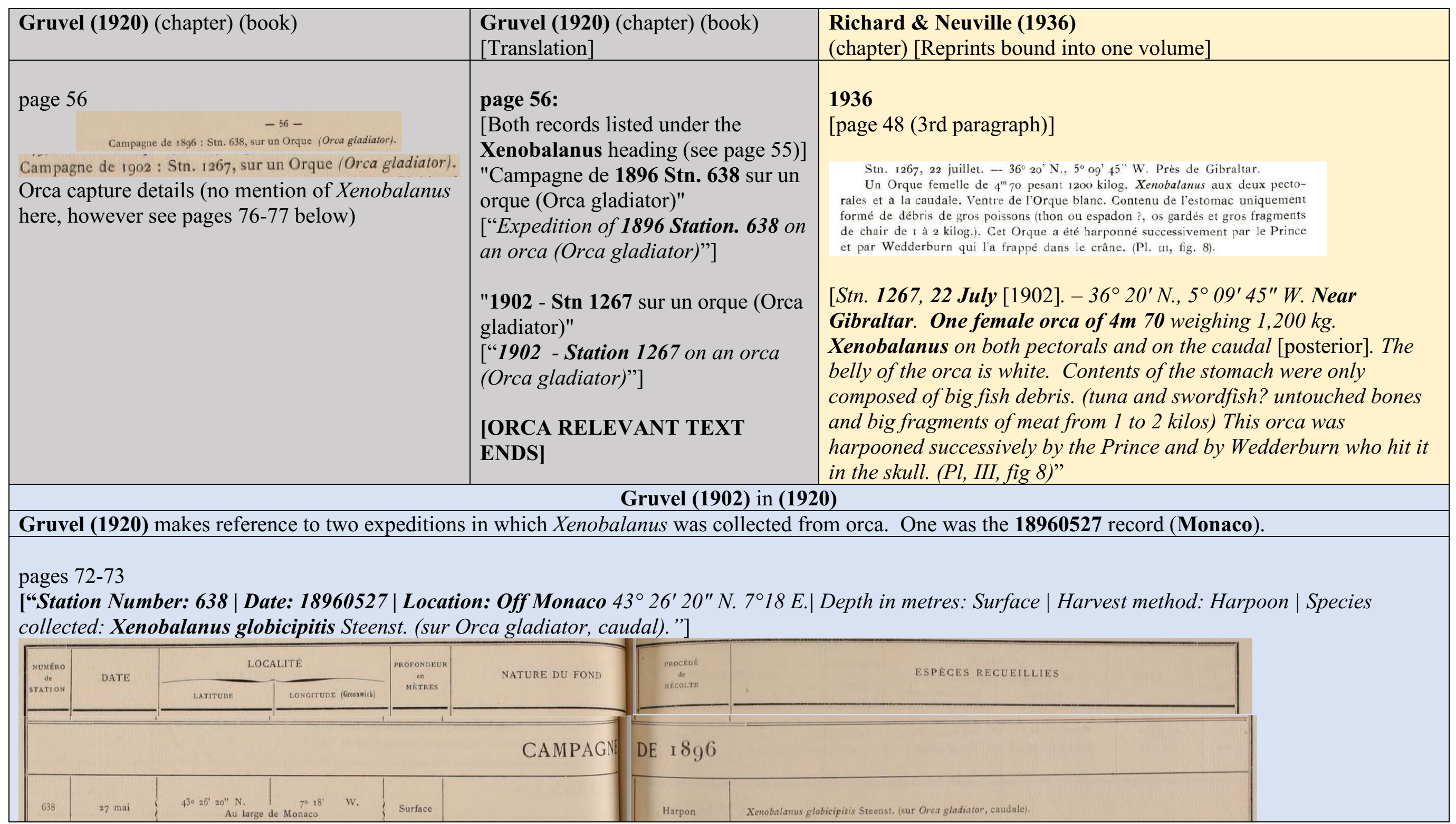


Gruvel (1920). An orca was captured on 19020722. This is the same date as the 'near Gibraltar' record in Richard \& Neuville (1936), which was actually captured off the coast of La Chullera, Spain

pages 76-77 [“Station Number: $1267 \mid$ Date: 19020722 | Location: $36^{\circ} 20^{\prime}$ N. $5^{\circ} 09^{\prime} 45^{\prime}$ W. | Depth in metres: Surface | Harvest method: Harpoon | Species collected; Xenobalanus globicipitis Steenst. (sur Orca gladiator)."]

\begin{tabular}{|c|c|c|c|c|c|c|c|}
\hline \multirow{2}{*}{$\begin{array}{c}\text { NUMÉro } \\
\text { de } \\
\text { stition }\end{array}$} & \multirow{2}{*}{ DATE } & \multicolumn{2}{|c|}{ LOCALITE } & \multirow{2}{*}{$\begin{array}{c}\text { PROFONDEUR } \\
\text { en } \\
\text { MEETRES }\end{array}$} & \multirow{2}{*}{ NATURE DU FOND } & \multirow{2}{*}{$\begin{array}{c}\text { PROCĖ̀É } \\
\text { de } \\
\text { rícoLTE }\end{array}$} & \multirow{2}{*}{ ESPECES RECUEILLIES } \\
\hline & & LATITUDE & LONGITUDE (Greenwieli) & & & & \\
\hline & & & & & CAMPAG & DE I 90 & \\
\hline 1267 & 22 juillet & $360^{\circ} 20^{\circ}$ & 5o og $45^{\prime \prime \prime} \mathrm{W}$. & Surface & & Harpon & Xenobalanus globicipitis Steenst. (sur Orca gladiator). \\
\hline
\end{tabular}

The only 1902 citation in Gruvel (1920) is

Gruvel J.A. (1902). Chapter 1, Expéditions scientifiques du "Travailleur" et du "Talisman" : Cirrhipèdes. Paris 1902.

This was a chapter in the book:

In: A M-E \& Perrier E, editors. Expéditions scientifiques du "Travailleur" et du "Talisman" Pendant les années 1880, 1881, 1882, 1883.

Masson et Cie, Éditeurs, Libraires de L'Académie de Médecine. Paris, 1-178 + VII Plates.

NOTE: there is no mention of any orca captures and the only mention of Xenobalanus is a generalised description of the barnacle and that it is "found on whales" [transaltaion]. Therefore, the Gruvel (1920) publication appears to be the first documentation of the 19020722 La Chullera,

Spain record. page 87 Index Bibliography

1902 reference highlighted.

It is possible that the 1902 record of Xenobalanus globicipitis on Orcinus gladiator is contained within this reference

\begin{tabular}{|c|c|}
\hline & INDEX BIBLIOGRAPHIQUE' \\
\hline $19 \circ 6$. & 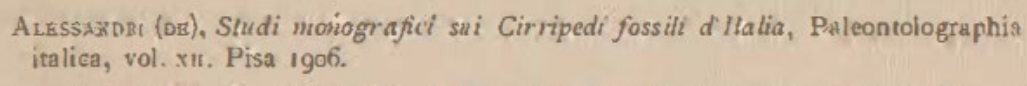 \\
\hline 1911. & 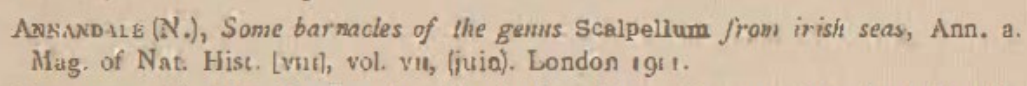 \\
\hline 1894. & $\begin{array}{l}\text { Auritin Lus (C. W.), Studien über Cirripedien, Kong. Sweaska Vet. Acad. Handl, } \\
\text { vol. } 26, \pi^{\circ} 7 \text {. Stockholm } 1894 .\end{array}$ \\
\hline 1898. & 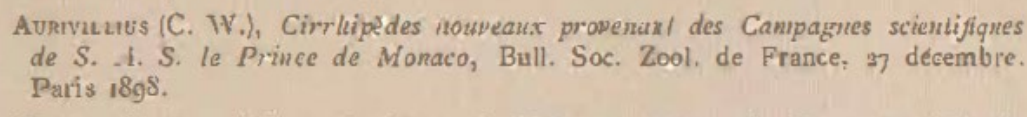 \\
\hline & 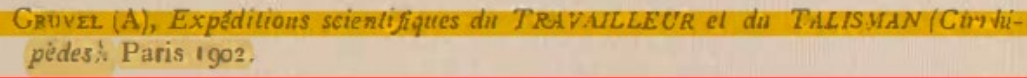 \\
\hline
\end{tabular}


Table S-1.3 For clarity and to ensure that this record is not conflated with the two previous records already discussed in Tables S-1.1, S-1.2.

Two mandibles from an orca (purchased from the Azores) are illustrated in both Richard \& Neuville (1897) and Richard \& Neuville (1936). Xenobalanus globicipitis is not associated with this record.

\begin{tabular}{|c|c|c|}
\hline 1897 (scientific journal publication) & 1936 (chapter) [Reprints bound into one volume] & Comparisons, Notes $(+$ translations $)$ \\
\hline $\begin{array}{l}\text { Page \# } 108 \text { Pl. VIII Cetacean catches during } \\
\text { Princess Alice campaign } \mathbf{1 8 9 6 .} \\
\text { (Fig 1).Note: No caption with the plate, just } \\
\text { reference to it in the text. }\end{array}$ & $\begin{array}{l}\text { Page \# 98/104 DOC. CÉTACÉS Pl.VII. } \\
\text { Figure } 11 .\end{array}$ & $\begin{array}{l}\text { These orca mandibles are from the Azores and not } \\
\text { associated with the captures in Monaco or Spain. } \\
\text { Photographs are identical. } \\
1897 \\
1936\end{array}$ \\
\hline 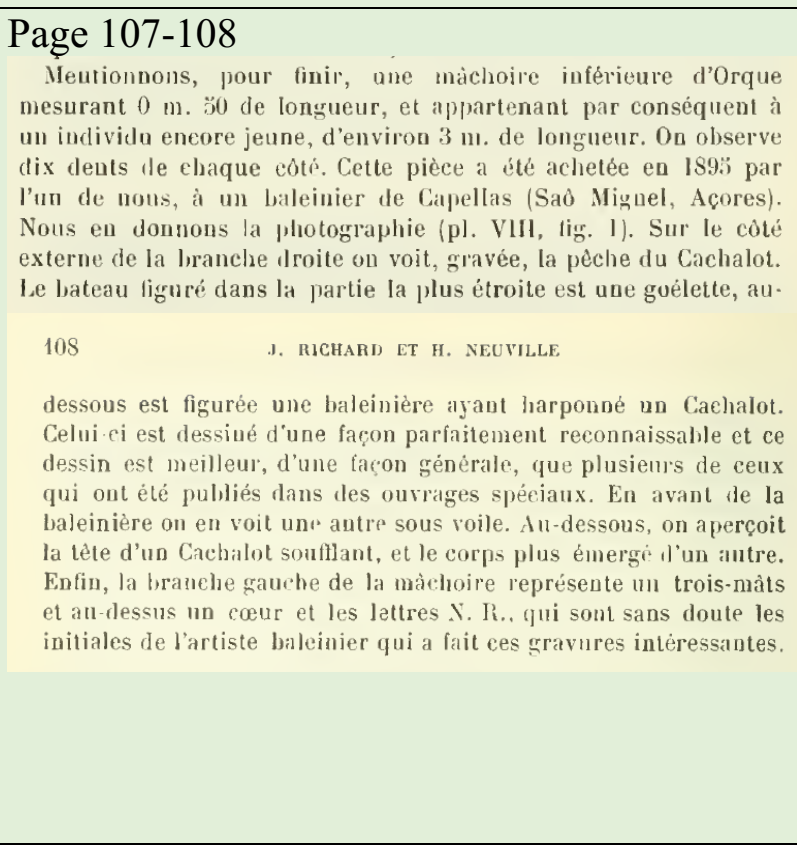 & 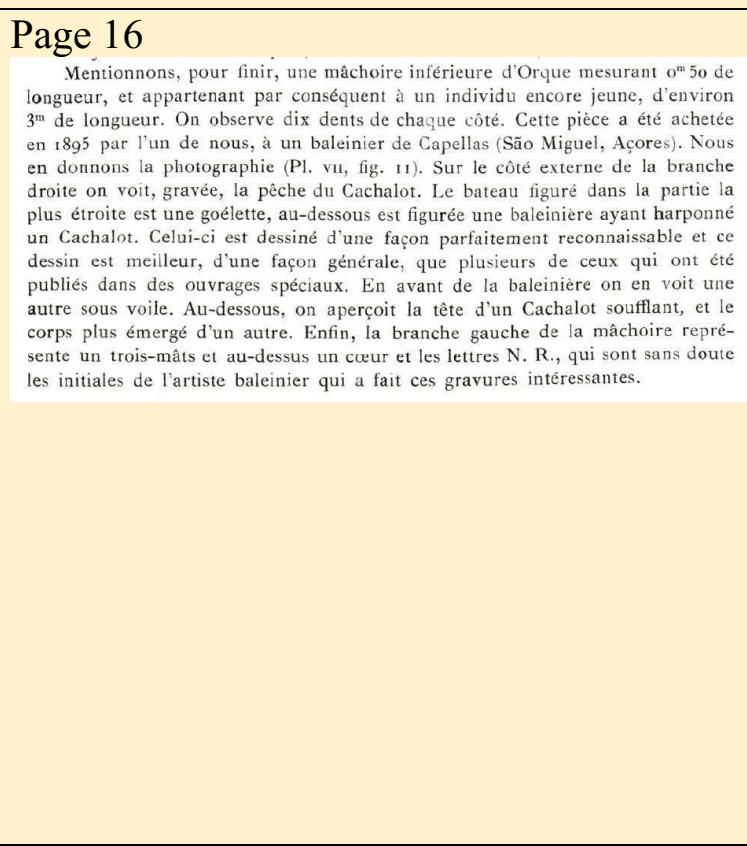 & $\begin{array}{l}\text { Text is identical (except Plate \& Fig. numbers) } \\
\mathbf{1 8 9 7} \& \mathbf{1 9 3 6} \\
\text { "Finally, let us mention an orca lower jaw measuring Om50 in } \\
\text { length so consequently belonging to a still young individual of } \\
\text { approximately } 3 \text { m long. There are ten teeth on each side. This } \\
\text { piece was purchased in } 1895 \text { by one of us from a whaling ship of } \\
\text { Gapellas (São Miguel, Azores). We present a photograph (Pl. VII, } \\
\text { Fig. 11). On the outer side of the right jaw we see, engraved, } \\
\text { hunting of the sperm whale. The boat shown on the narrower } \\
\text { section is a schooner, below is a whaling boat having harpooned } \\
\text { a Cachalot [sperm whale]. This one is drawn in a perfectly } \\
\text { recognizable way and this drawing is better, in general, than } \\
\text { many of those that have been published in special works. In front } \\
\text { of the whaling boat we see one other under sail. Below, we see the } \\
\text { head of a whale blowing, and the body more emerged from } \\
\text { another. Finally, the left side of the jaw represents a three-masted } \\
\text { ship and above it a heart and the letters N. R., which are } \\
\text { undoubtedly the initials of the whaling artist who made these } \\
\text { interesting prints." [translation] }\end{array}$ \\
\hline
\end{tabular}


Supplemental Material S-2. Details and counts of Xenobalanus for each appendage of orca NZOP-005. Details and counts of Xenobalanus globicipitis (hereafter referred to as Xenobalanus). Images were post-process with TopazLab Stabilise AI and Gigapixel $\mathrm{AI}^{1}$ and assessed at $>200 \%$ magnification on a high-definition screen. Although the resulting photographs may have lost some finer details, the overall results allowed for more accurate counts than would be possible with the RAW files from the camera alone.

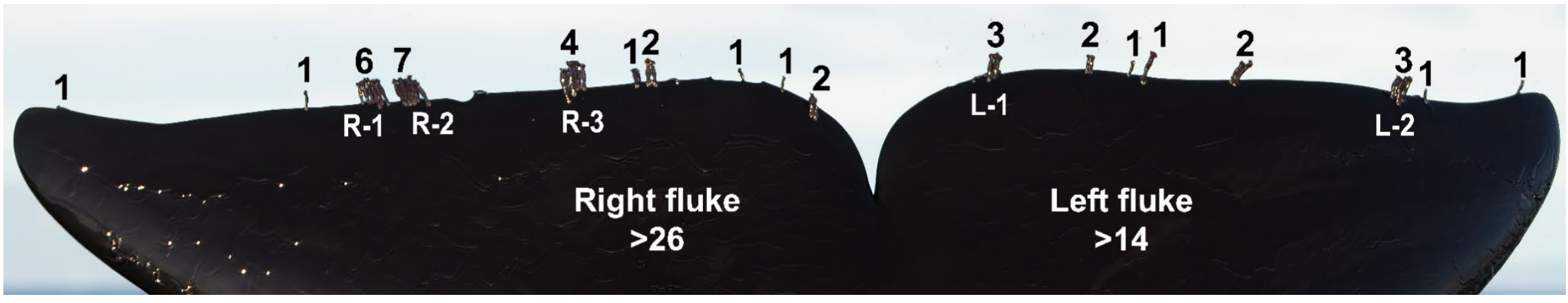

Figure S-2.1 Dorsal view of both tail flukes of NZOP-005 showing Xenobalanus clusters (three or more very close together, labelled as R1R3 and L1-L2). Singles or pairs are labelled separately. Sub-totals are given on each fluke in white text. See Fig. S-2.2-S-2.5 for details.

\begin{tabular}{|c|c|c|}
\hline \multirow{2}{*}{$\begin{array}{c}* \\
\text { FLUKE }\end{array}$ CLUSTERS } & RIGHT & LEFT \\
\cline { 2 - 3 } & $\mathrm{R}-1, n=6$ & $\mathrm{~L} 1, n=3$ \\
\cline { 2 - 3 } & $\mathrm{R}-2, n=7$ & $\mathrm{~L} 2, n=3$ \\
\cline { 2 - 3 } & $\mathrm{R}-3, n=4$ & - \\
\hline FLUKE & $n=9$ & $n=8$ \\
\hline SINGLES \& PAIRS & $n=>\mathbf{2 6}$ & $n=>\mathbf{1 4}$ \\
\hline Totals & &
\end{tabular}

Table S-2. 1. Minimum numbers of Xenobalanus on tail flukes of NZOP-005.

${ }^{1}$ https://topazlabs.com/ 


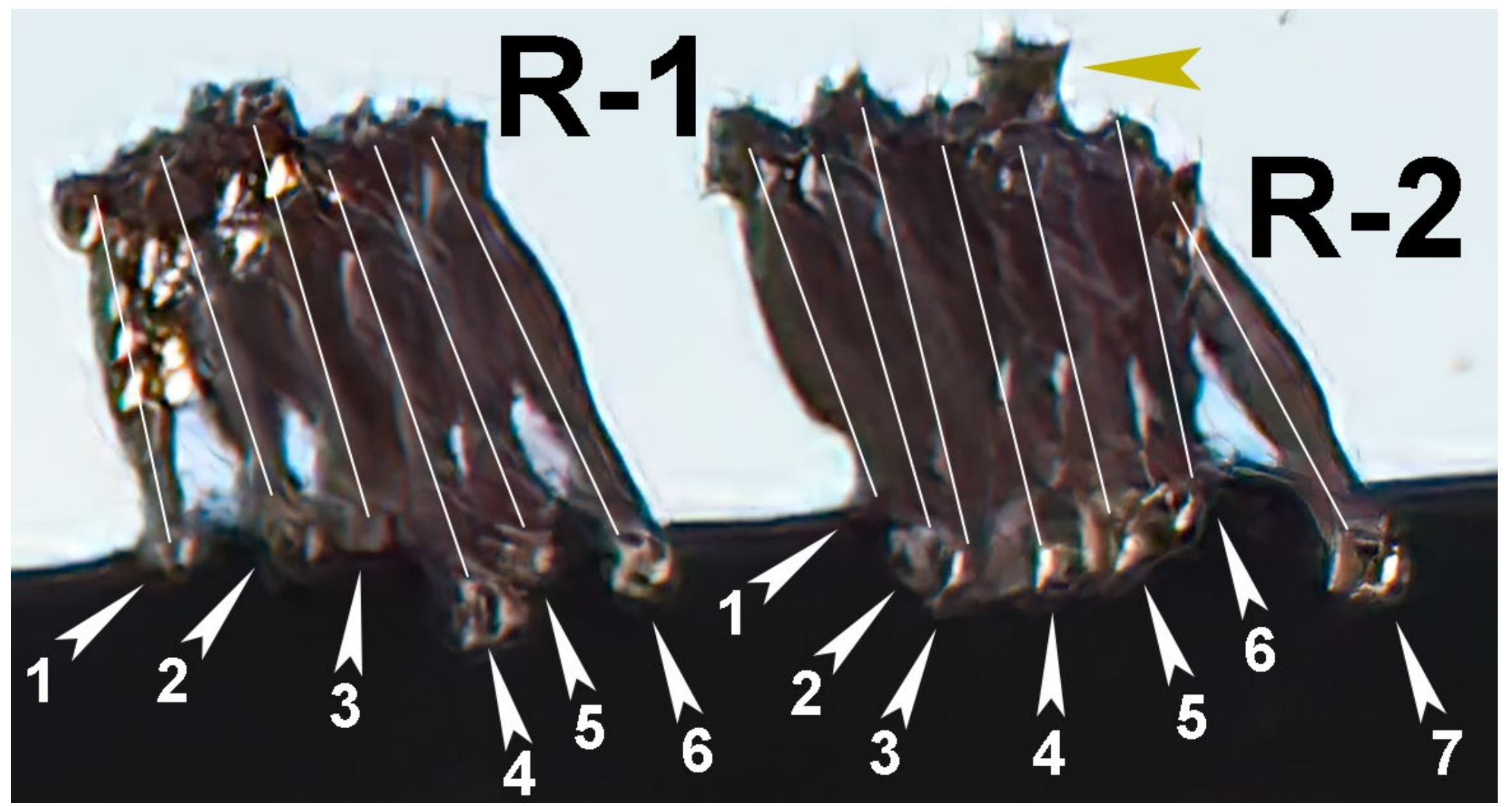

Figure S-2.2 Close-up of Xenobalanus clusters R-1 \& R-2 (see Fig. S-2.1 for placement on right fluke). Labelling was done by assessing basal plates (typically indicated by a pale area, or a rounded area of similar size to its conspecifics) and drawing a line between the base and the head of the barnacle (white lines). R-1 has at least six barnacles and R2 has at least seven. The yellow arrow indicates a possible $8^{\text {th }}$ Xenobalanus in cluster R-2, which was not included in the count in Table S-2.1. 


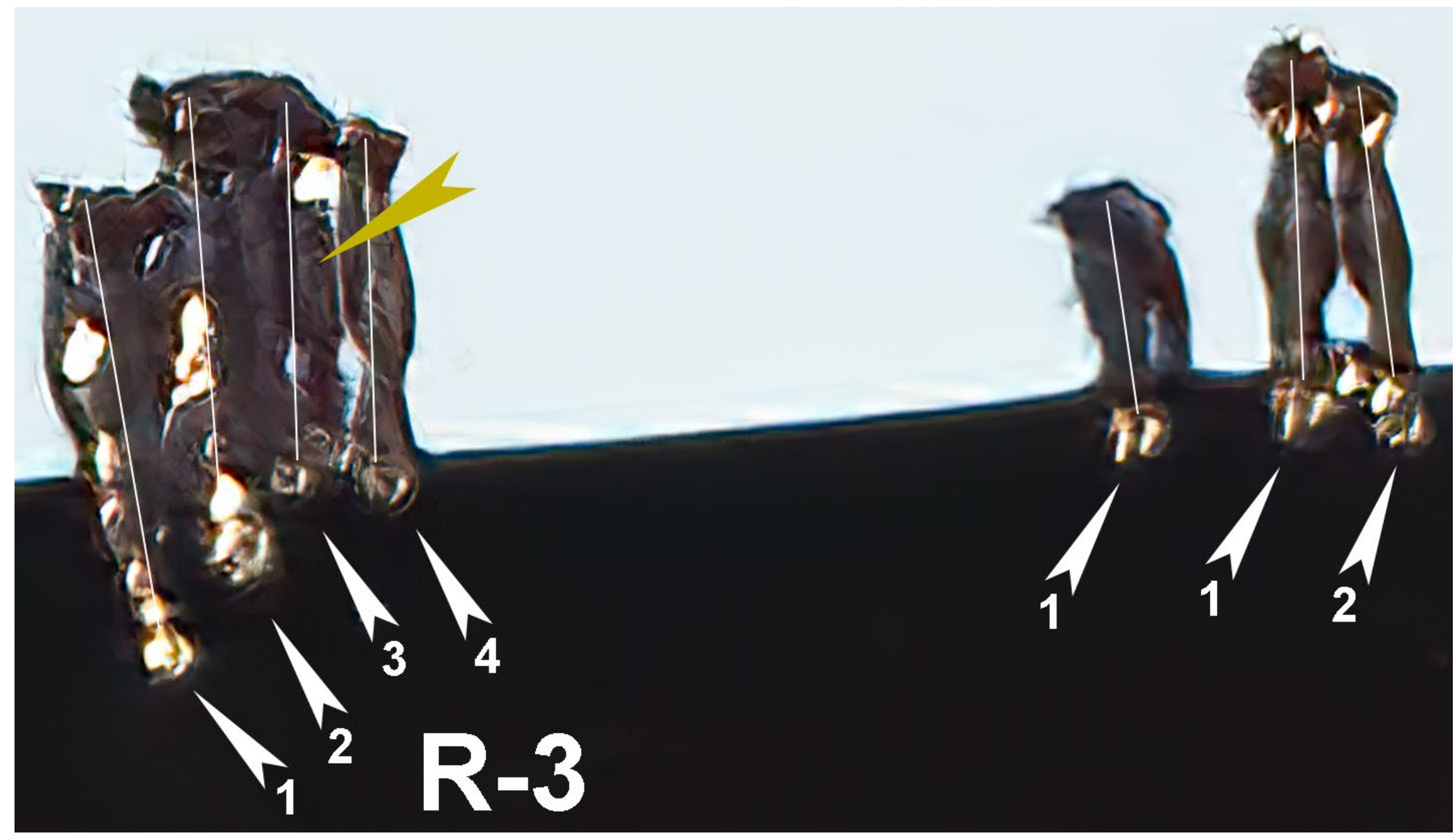

Figure S-2.3. Close-up of R-3 with four barnacles. To the right of R-3 are three barnacles (a single and a pair) which are more widely spaced (see Fig. S-2.1 for placement on right fluke). The yellow arrow indicates a possible $4^{\text {th }}$ Xenobalanus in cluster R-3. This was not included in the count in Table S-21. 


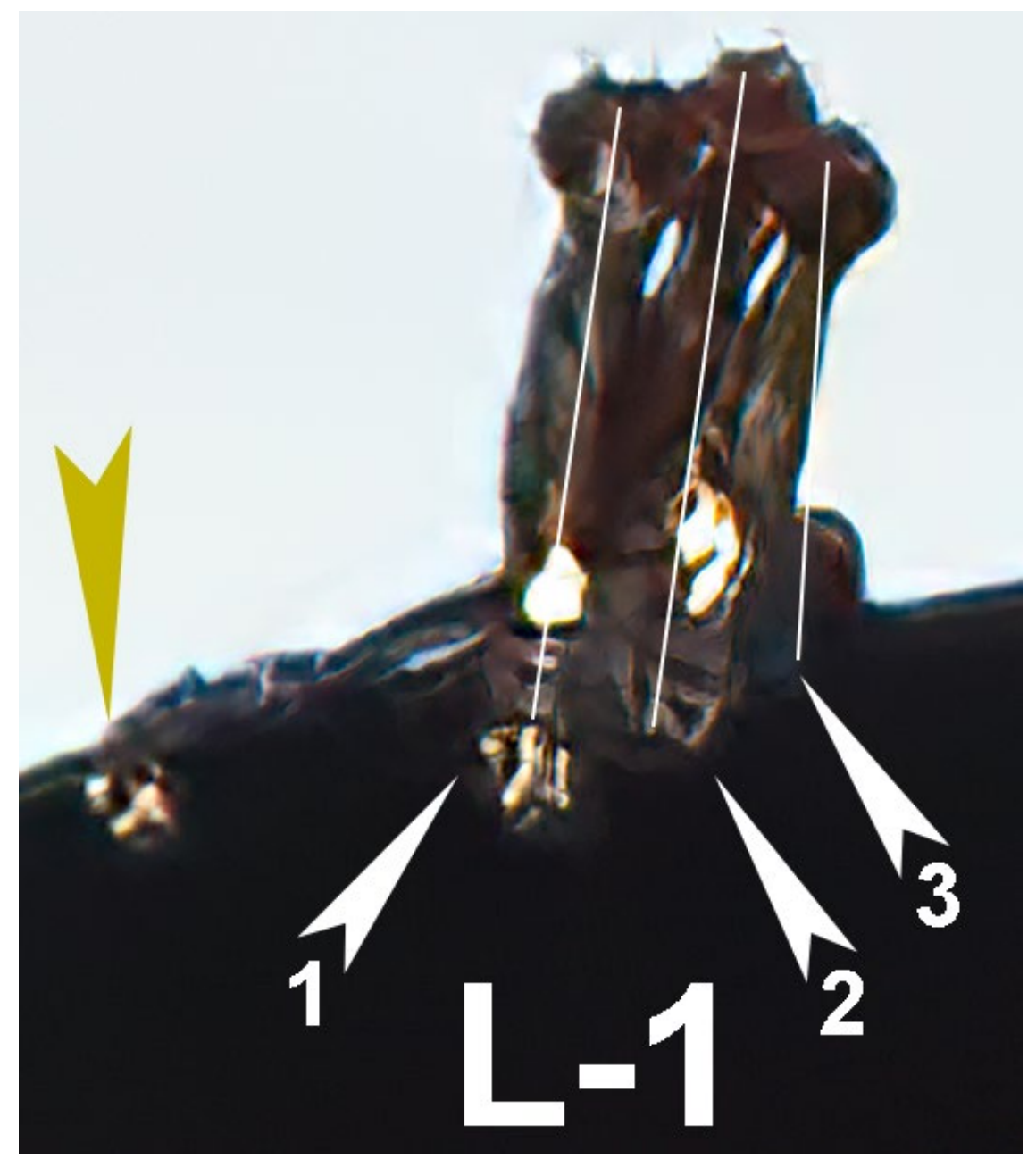

Figure S-2.4. Close-up of L-1 (see Fig. S-2.1 for placement on left fluke). The yellow arrow indicates a possible $4^{\text {th }}$ Xenobalanus, which appears to be lying flat and in behind L-1, which was not included in the count in Table S-2.1. 


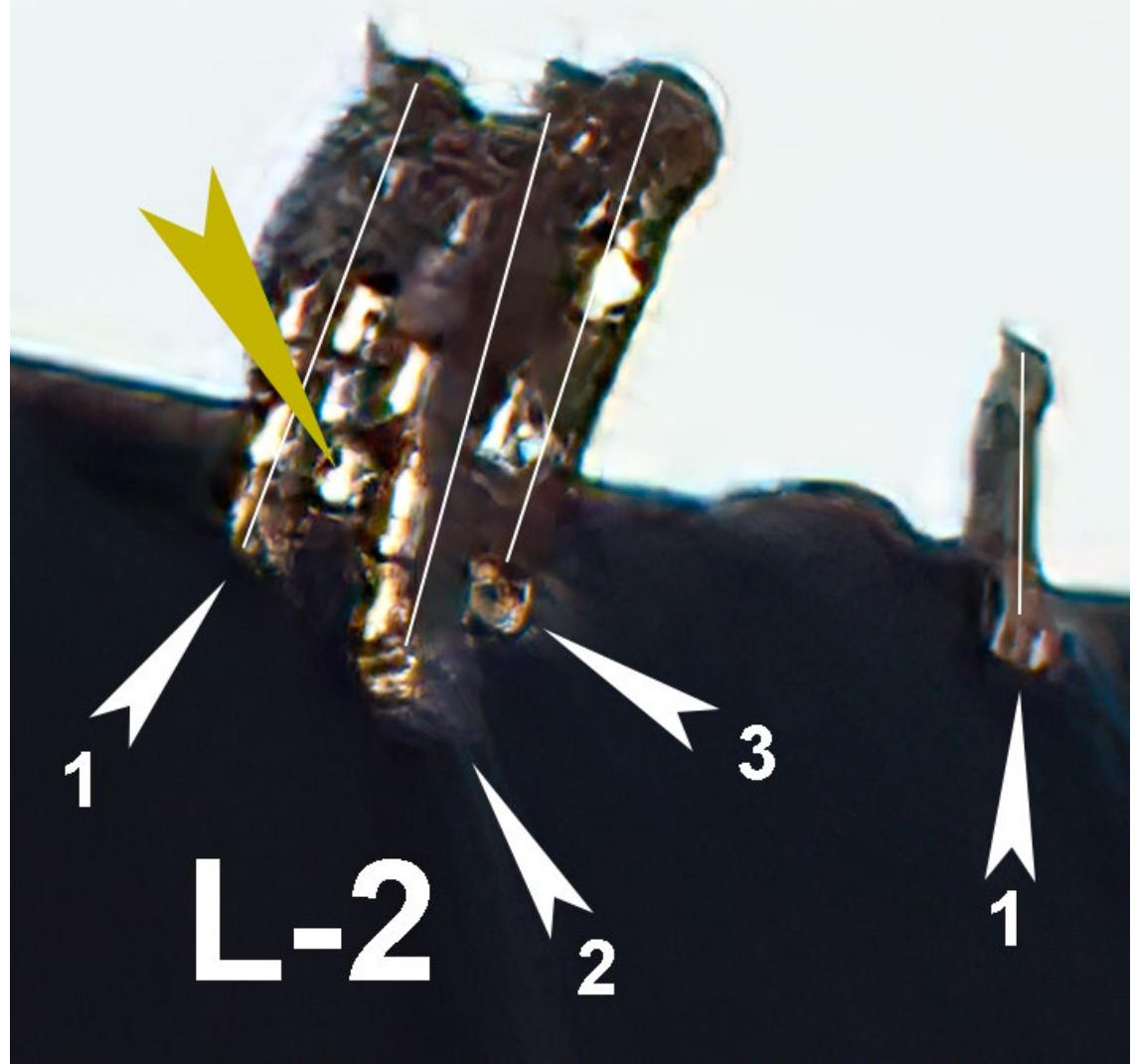

Figure S-2.5. Close-up of L-2 (see Fig. S-2.1 for placement on left fluke). Yellow arrow indicates a possible $4^{\text {th }}$ Xenobalanus in L-2, which was not included in the count in Table S-2.1. 


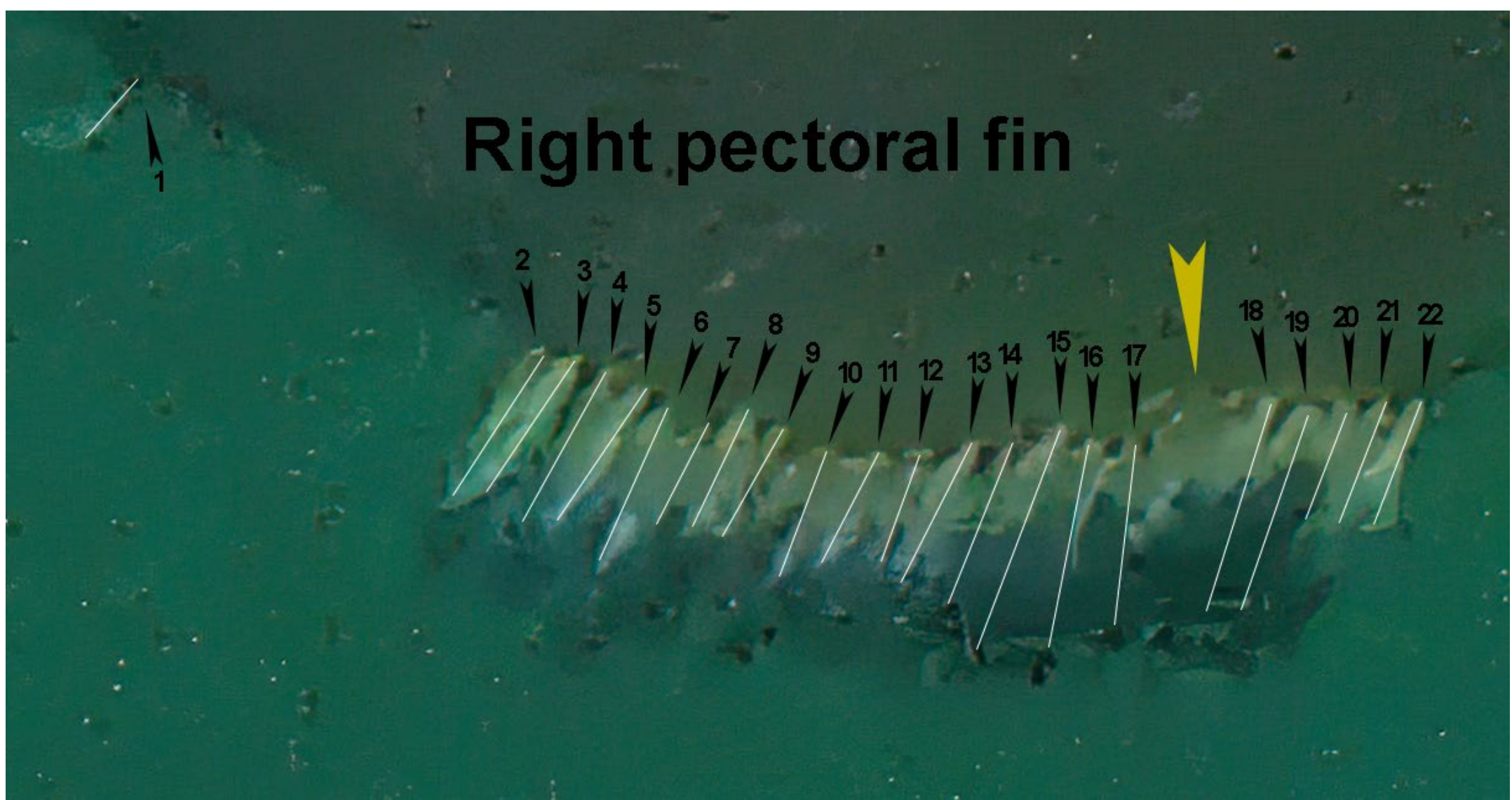

Figure S-2.6. Close-up of right pectoral fin, showing $>22$ Xenobalanus. One barnacle (\#1) is at the left of the frame. The yellow arrow indicates an area where it was not possible to count how many barnacles were present but based on the spacing of the barnacles on either side, there may be three or more. These were not included in the count in Table S-2.2. 


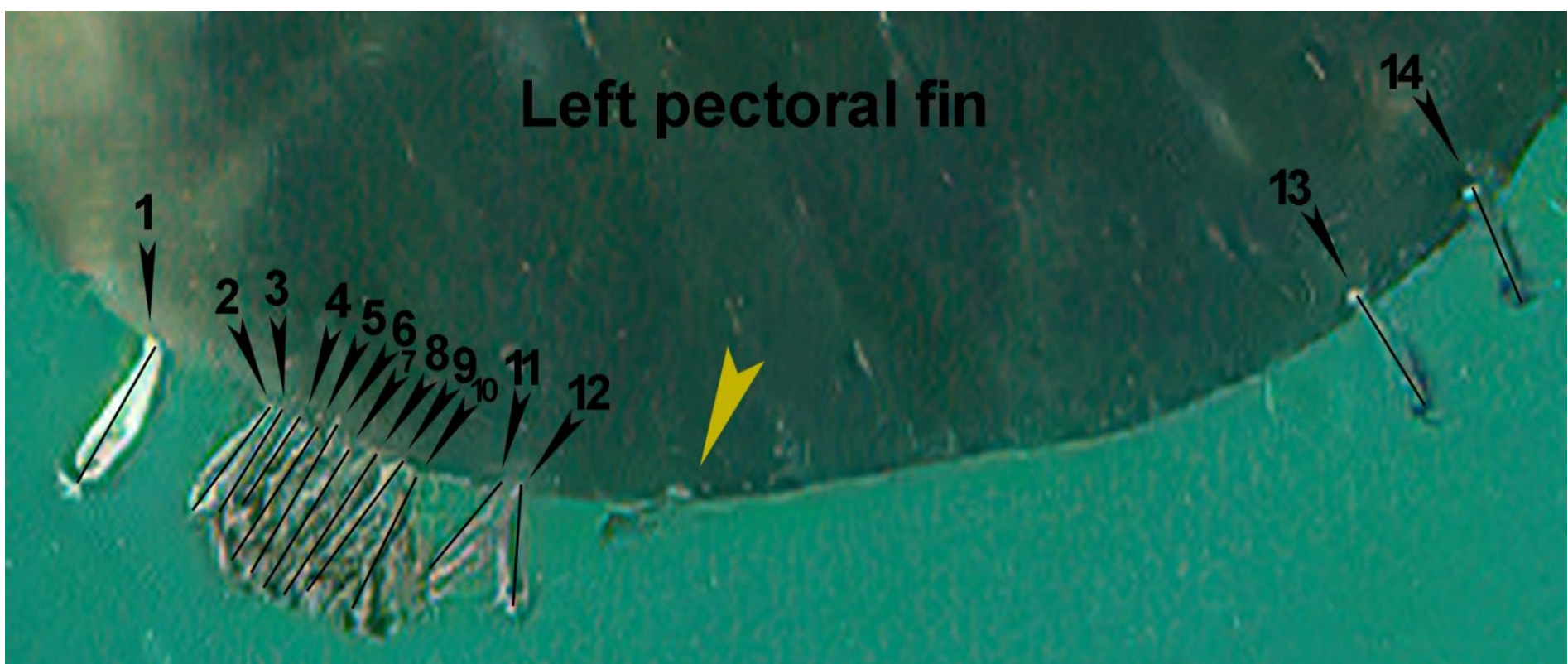

Figure S-2.7. Close-up of left pectoral fin. The yellow arrow indicates a possible $15^{\text {th }}$ Xenobalanus, which was not included in the count in Table S-2.2.

\begin{tabular}{|c|c|c|c|}
\hline & RIGHT & LEFT & $\begin{array}{c}\text { APPENDAGE } \\
\text { TOTAL }\end{array}$ \\
\hline FLUKE & $n=>26$ & $n=>14$ & $n=>40$ \\
\hline PECTORAL & $n=>22$ & $n=>14$ & $n=>36$ \\
\hline subtotals & $n=48$ & $n=28$ & - \\
\hline DORSAL FIN & \multicolumn{3}{|c|}{$n=3$} \\
\hline TOTAL & \multicolumn{3}{|c|}{$n=3$} \\
\hline
\end{tabular}

Table S-2.2. Numbers of Xenobalanus on appendages of NZOP-005, with higher numbers on her right side. The total number of $>79$ is conservative, given that clusters can obscure individuals and movement of appendages can result in some barnacles not being visible at all times. 